\title{
ORNL ADCP POST-PROCESSING GUIDE AND MATLAB ALGORITHMS FOR MHK SITE FLOW AND TURBULENCE ANALYSIS
}

September 2011

\section{Prepared by}

Budi Gunawan, Ph.D.

Vincent S. Neary, Ph.D., P.E. 


\section{DOCUMENT AVAILABILITY}

Reports produced after January 1, 1996, are generally available free via the U.S. Department of Energy (DOE) Information Bridge.

Web site http://www.osti.gov/bridge

Reports produced before January 1, 1996, may be purchased by members of the public from the following source.

National Technical Information Service

5285 Port Royal Road

Springfield, VA 22161

Telephone 703-605-6000 (1-800-553-6847)

TDD 703-487-4639

Fax 703-605-6900

E-mail info@ntis.gov

Web site http://www.ntis.gov/support/ordernowabout.htm

Reports are available to DOE employees, DOE contractors, Energy Technology Data Exchange (ETDE) representatives, and International Nuclear Information System (INIS) representatives from the following source.

Office of Scientific and Technical Information

P.O. Box 62

Oak Ridge, TN 37831

Telephone 865-576-8401

Fax 865-576-5728

E-mail reports@osti.gov

Web site http://www.osti.gov/contact.html

This report was prepared as an account of work sponsored by an agency of the United States Government. Neither the United States Government nor any agency thereof, nor any of their employees, makes any warranty, express or implied, or assumes any legal liability or responsibility for the accuracy, completeness, or usefulness of any information, apparatus, product, or process disclosed, or represents that its use would not infringe privately owned rights. Reference herein to any specific commercial product, process, or service by trade name, trademark, manufacturer, or otherwise, does not necessarily constitute or imply its endorsement, recommendation, or favoring by the United States Government or any agency thereof. The views and opinions of authors expressed herein do not necessarily state or reflect those of the United States Government or any agency thereof. 
Environmental Science Division

\section{ORNL ADCP POST-PROCESSING GUIDE AND MATLAB ALGORITHMS FOR MHK SITE FLOW AND TURBULENCE ANALYSIS}

Budi Gunawan, Ph.D.

Vincent S. Neary, Ph.D., P.E.

Date Published: September 30, 2011

Prepared by

OAK RIDGE NATIONAL LABORATORY

Oak Ridge, Tennessee 37831-6283

managed by

UT-BATTELLE, LLC

for the

U.S. DEPARTMENT OF ENERGY under contract DE-AC05-00OR22725 


\section{LIST OF CONTENTS}

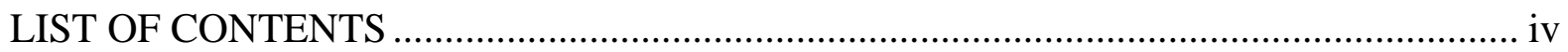

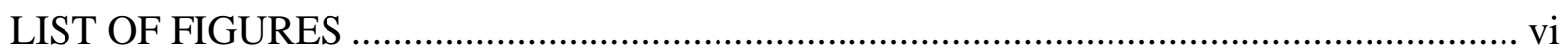

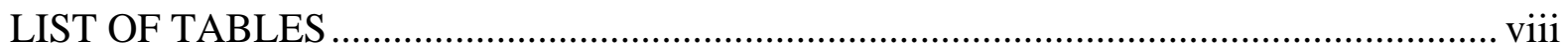

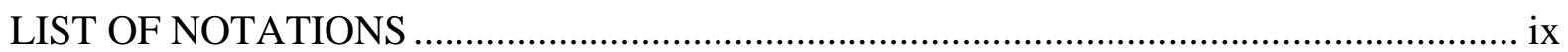

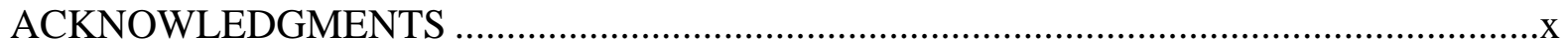

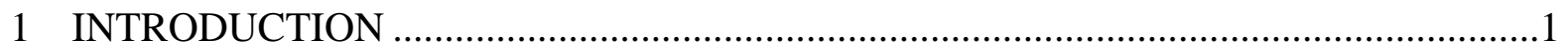

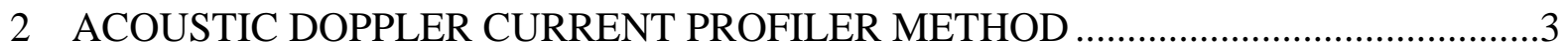

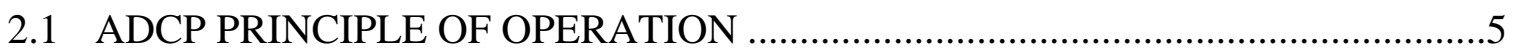

2.1.1 Doppler shift principle...................................................................... 5

2.1.2 The broadband ADCP ………………….............................................. 7

2.1.3 Bin depth computation ............................................................................. 8

2.1.4 Transformation from beam to orthogonal coordinate system ....................... 9

2.1.5 Bottom tracking ...................................................................................... 10

2.2 ADCP MEASUREMENT AND DEPLOYMENT METHODS ...............................10

2.3 ADCP MEASUREMENT UNCERTAINTY ............................................................12

2.3.1 3D velocity sampling volume................................................................ 12

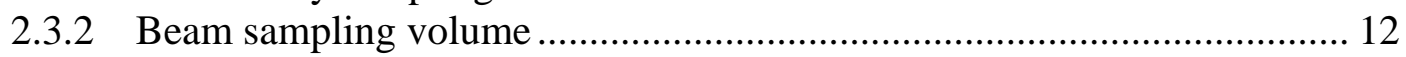

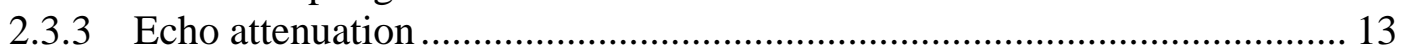

2.3.4 Lack of scatterers.............................................................................. 13

2.3.5 Side lobe interference ........................................................................... 13

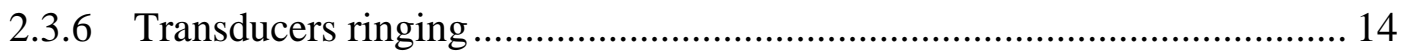

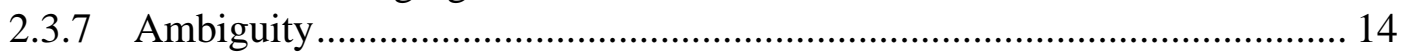

2.3.8 Moving-bed condition ................................................................................... 15

2.3.9 The presence of submerged vegetation ..................................................... 15

2.3.10 Air bubbles .......................................................................................... 15

2.4 PROTOCOLS FOR REDUCING ERROR …………..........................................15

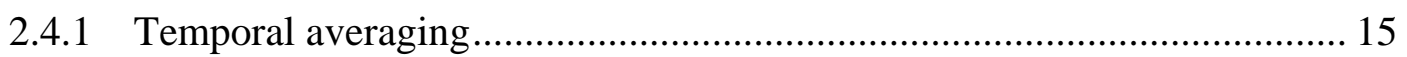

2.4.2 Spatial averaging ……………………………….................................. 16

2.4.3 Histogram inspection............................................................................. 19

2.4.4 Spike identification, removal and replacement .......................................... 19

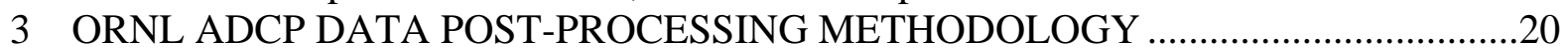

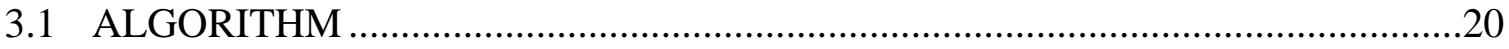

3.1.1 Phase-Space Thresholding method ......................................................... 21

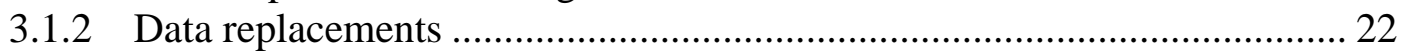

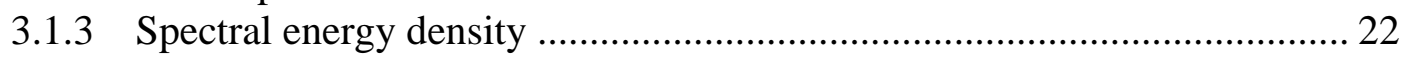

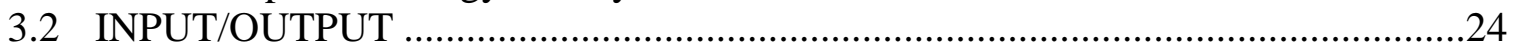

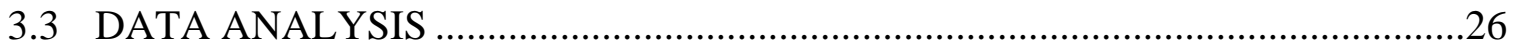

3.3.1 Description of the data .......................................................................... 26

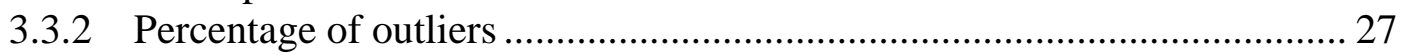

3.3.3 Mean velocity and velocity RMS (standard deviation) .................................. 31

3.3.4 Spectral energy density ............................................................................... 33 


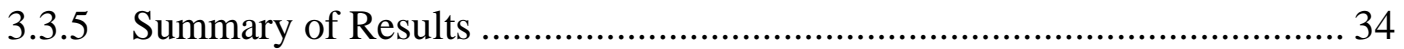

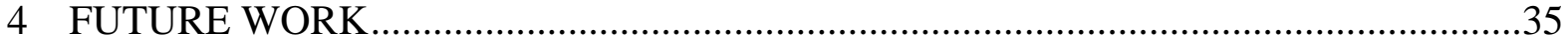

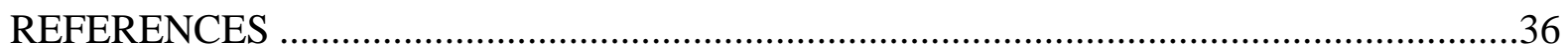

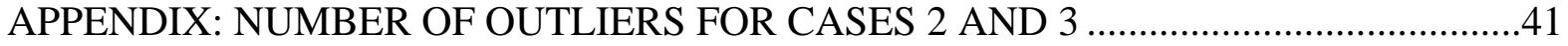




\section{LIST OF FIGURES}

Figure 1.1 Typical distributions of velocity and turbulence and sketch of horizontal-axis hydrokinetic turbine. Modified from Neary and Sale (2010). ..................................................... 1 Figure 2.1 Different types of ADCP beam configurations (RDI 2011a)....................................... 4 Figure 2.2 Contour of velocity magnitude in a river cross section measured using an RDI Rio Grande broadband ADCP (Gunawan 2010)........................................................................... 4 Figure 2.3 Variation of the streamwise velocity and standard deviation corresponding to a set of stationary measurements in a river (Gunawan et al. 2010a)........................................................... 4 Figure 2.4 The Doppler principle and a water-wave analogy (Simpson 2001) …......................... 5 Figure 2.5 Sound wave transmission and reflection by particles (Simpson 2001)........................ 6

Figure 2.6 Reflected pulse shows two Doppler Shifts (Simpson 2001). ....................................... 6 Figure 2.7 Transformation of velocity component into beam coordinate system (RDI 1996)...... 7 Figure 2.8 Acoustic pulses of narrow band and broadband ADCP technologies (Muller and

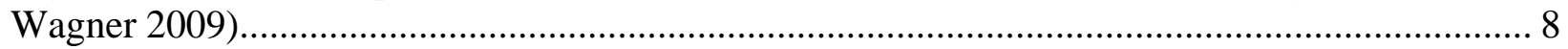

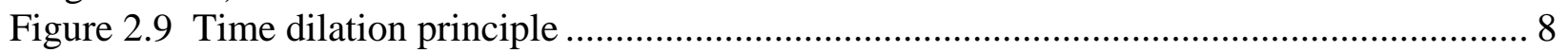

Figure 2.10 Beam velocity components (RDI, 1996)........................................................... 9

Figure 2.11 Velocity magnitude and direction in the E-W and N-S axis (RDI, 1996).................. 9 Figure 2.12 ADCP deployment methods: (a) mooring, (b) mounted, (c) underwater vehicle, (d) remote controlled boat (RDI 2011b; Muller and Wagner 2009). ............................................... 11 Figure 2.13 Two views of shipboard ADCP side-swing mount on a 30-meter (95-foot) vessel (Simpson 2001)............................................................................................................. 11 Figure 2.14 Left: schematic of a four-beam ADCP showing typical sampling volume (Neary et al. 2011a); right: non-homogeneous horizontal velocities (Simpson 2001).............................. 12 Figure 2.15 Contours of velocity magnitude at a location in Puget Sound, WA, obtained from an upward looking ADCP (courtesy of the Northwest National Marine Renewable Energy Center,

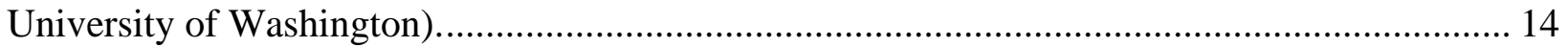

Figure 2.16 Conceptual layout with schematic of perturbed turbulent.......................................... 17 Figure 2.17 Results of ADCP transect averaging; top: contour of normalized streamwise velocity $(U / U)$, bottom: $V$ and $W$ velocity vectors (Gunawan 2010b)....................................... 18 Figure 2.18 Difference between $U_{d}$ values obtained from ADCP stationary measurements and ADCP transect averaging results at two cross sections (Gunawan 2010).................................... 18 Figure 3.1 Algorithm adopted for the ORNL ADCP data post-processing methodology - the steps in dashed line boxes are optional ......................................................................................... 21

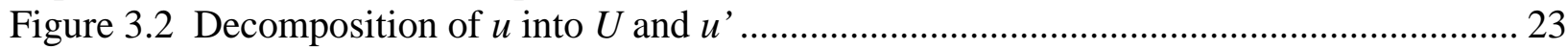

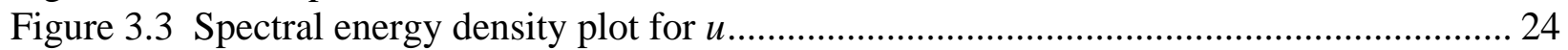

Figure 3.4 Input format for the ORNL ADCP stationary data post-processing code.................... 25

Figure 3.5 Measurement setting at the St. Anthony Falls Laboratory........................................... 26

Figure 3.6 The SonTek ADP used in the experiment............................................................. 27

Figure 3.7 Correlation value at one of the ADCP beams for the measurement at $1.0 \mathrm{~m}$ upstream

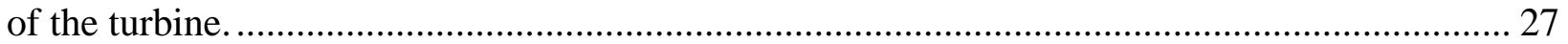

Figure 3.8 Number of outliers (in percent) at different bins for the $X$ velocity component at $1.0 \mathrm{~m}$ upstream of the turbine model. ................................................................................................. 28

Figure 3.9 Number of outliers (in percent) at different bins for the $Y$ velocity component at $1.0 \mathrm{~m}$ upstream of the turbine model. ............................................................................................... 29

Figure 3.10 Number of outliers (in percent) at different bins for the $Z$ velocity component at 
$1.0 \mathrm{~m}$ upstream of the turbine model.

Figure 3.11 Streamwise, lateral and vertical velocities with respect to distance from bed at $1.0 \mathrm{~m}$

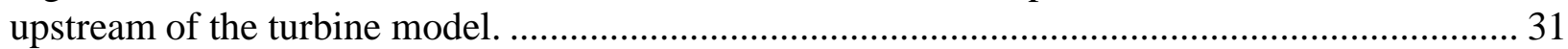
Figure 3.12 RMS values of streamwise, lateral and vertical velocities with respect to distance from bed at $1.0 \mathrm{~m}$ upstream of the turbine model............................................................. 32 Figure 3.13 RMS values of streamwise, lateral and vertical velocities with respect to distance from bed at 1.5m upstream of the turbine model................................................................... 32 Figure 3.14 RMS values of streamwise, lateral and vertical velocities with respect to distance from bed at $2.5 \mathrm{~m}$ upstream of the turbine model................................................................... 33 Figure 3.15 SED plot for the streamwise velocity at 1.0m upstream of the turbine model (at the turbine hub height, $z=0.425 \mathrm{~m}$ ). 


\section{LIST OF TABLES}

Table 2.1 Minimum averaging time for ADCP stationary measurement in rivers suggested by

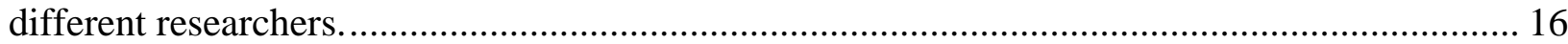

Table 3.1 Output file generated by ORNL ADCP data post-processing code........................... 25 Table 3.2 Reduction of $u^{\prime}$ after applying PST and mPST filtering (in percentage from the raw data) at $1.0 \mathrm{~m}, 1.5 \mathrm{~m}$ and $2.5 \mathrm{~m}$ upstream of the turbine model. 33 


\section{LIST OF NOTATIONS}

$\alpha \quad$ the angle between the velocity vector and the transducer beam

(degree)

$(\mathrm{dB} / \mathrm{m})$

$\beta \quad$ absorption coefficient

$\left(\mathrm{ms}^{-1}\right)$

$C$ speed of sound

C1 first reconstruction constant, a calibration parameter in mPST

C2 second reconstruction constant, a calibration parameter in mPST

$d_{s} \quad$ cylinder diameter

$d_{t} \quad$ turbine blade diameter

EI echo intensity

$f \quad$ frequency band

$f_{R} \quad$ sampling frequency

$f_{s} \quad$ shedding frequency

$F_{D} \quad$ Doppler Shift frequency

$F_{S} \quad$ frequency of the source

$H \quad$ flow depth in the main channel

RMS

energy containing length scale/macroscale turbulence

root mean square or standard deviation, $\sqrt{\frac{\sum x_{i}^{2}}{n}}$

$R \quad$ distance from the transducer to the depth cell

$R_{u и} \quad$ autocorrelation of the streamwise velocity component

standard deviation of velocity

$S \quad$ frequency of the transmitted sound

SL $\quad$ source level or transmitted power

$S_{u} \quad$ Fourier transform of $u u$

$S V \quad$ water-mass volume backscattering strength

$u \quad$ instantaneous velocity in the streamwise direction

$u$ ' instantaneous velocity fluctuation in the streamwise direction

$U$ mean streamwise velocity with respect to time

$\bar{U} \quad$ cross section mean streamwise velocity

$U_{c} \quad$ convective velocity

$U_{d} \quad$ depth-averaged streamwise velocity

$U_{\text {in }} \quad$ inflow mean streamwise velocity

$U_{\text {out }} \quad$ outflow mean streamwise velocity

$U_{R M S} \quad$ RMS value of the streamwise velocity

$v$, instantaneous velocity fluctuation in the lateral direction 


\section{ACKNOWLEDGMENTS}

The authors thank DOE/EERE for supporting the development of the ORNL post-processing algorithms under CPS Project No. 20689, CPS Agreement Nos. 20065 and 20070. The pst_outlier, pst, mpst_outlier and mpst algorithms as they appear in the appendix originated from algorithms developed by Nobuhito Mori, of Tokyo University in Japan, who maintains a GNU license to the algorithms. The authors also thank Dr. Leonardo Chamorro, Mr. Craig Hill and Mr. Scott Morton from the St. Anthony Falls Laboratory (SAFL), Minneapolis, Minnesota, for providing the original algorithm for plotting Power Spectral Density and acoustic Doppler current profiler data from the SAFL, main channel. Student interns who assisted with MATLAB code development and testing include James McNutt, Bennett Flanders, Pablo Rosado, Danny Sale, Andrew Hansen and Sreekanth Bangaru. 


\section{INTRODUCTION}

Measurements of mean velocity, Reynolds stresses and turbulence spectra are desirable for marine and hydrokinetic (MHK) device testing, site development and environmental monitoring. The acoustic Doppler current profiler (ADCP) is the most practical and economical instrument for obtaining instantaneous velocity profile measurements from which the mean velocity profile can be calculated. Turbulent stresses from ADCP measurements, however, are generally not accurate due to the instrument's relatively low sampling frequency, spatial averaging over large sample volumes and multibeam configuration (Muste et al. 2004, Neary et al. 2011b), and low sampling frequencies typically preclude analysis of turbulence spectra. The maximum sampling volume and the minimum sampling frequency of an instrument to be able to analyze the spectral distribution down to the viscous subrange are outlined in Nezu and Nakagawa (1993). Typical profiles, illustrated in Figure 1.1, allow assessment of the hydrodynamic forces acting on the hydrokinetic device and the power density and power available over the energy extraction plane (EEP). This data informs the MHK device and component design and estimation of performance curves, annual energy production (AEP) and cost of energy (COE).

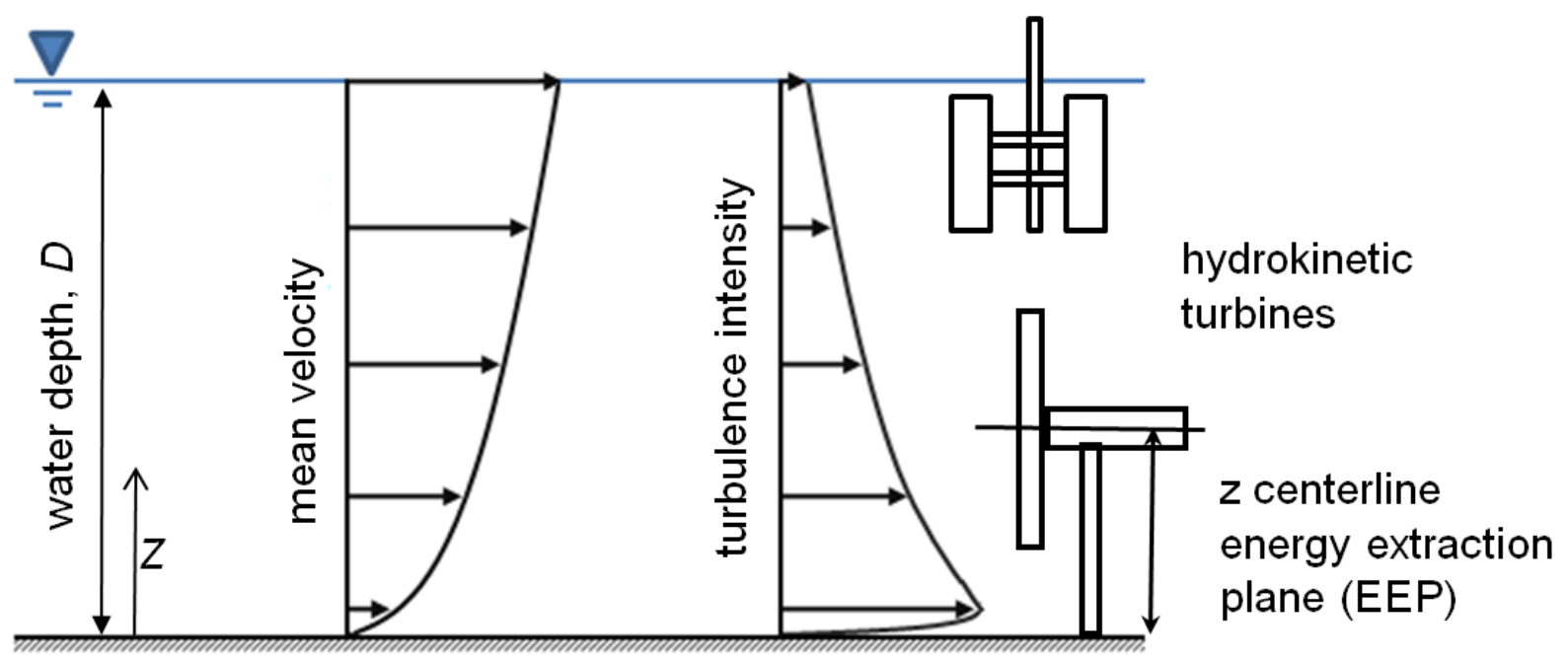

Figure 1.1 Typical distributions of velocity and turbulence and sketch of horizontal-axis hydrokinetic turbine. Modified from Neary and Sale (2010).

Velocity data obtained using ADCPs contain errors that appear as spikes in the data due to some limitations inherent in the ADCP system. These errors can be reduced by applying spike detection and removal, and temporal or spatial averaging algorithms. Given these challenges, there is a need to test and validate turbulent flow field measurement protocols, instrument packages, deployment strategies, and turbulence post-processing algorithms. To the authors' knowledge there are currently no standard protocols for post-processing ADCP measurements to ensure accuracy of velocity and turbulence data. There are also no standard post-processing algorithms that are consistently used for laboratory and field measurements. Standard methods, along with guidance for post-processing the ADCP stationary measurements using MATLAB 
algorithms that were evaluated and tested by Oak Ridge National Laboratory (ORNL), are presented following an overview of the ADCP operating principles, deployment methods, error sources and recommended protocols for removing and replacing spurious data. The spatial and temporal averaging algorithm for the ADCP shipboard data is currently under development, and is expected to be incorporated in this report by September 2012. 


\section{ACOUSTIC DOPPLER CURRENT PROFILER METHOD}

An ADCP measures velocity based on the Doppler principle and, depending on its type and deployment method, can also be utilized to measure bed profiles or water surface elevations. The ADCP is as an adaptation of a speed log, an instrument used to measure the speed of ships, which was introduced in the mid-1970s (Rowe and Young 1979). ADCPs have two to five transducers that also act as receivers of the backscattered pulses (Figure 2.1). The first generations of ADCPs, often termed as narrow band or pulse incoherent ADCPs, utilized a single pulse in each ping for each velocity measurement. In the early 1990s the broadband ADCP was introduced. Each ping for the broadband ADCP consists of multiple short pulses, which results in a higher number of samples within a single ping when compared to the narrowband ADCP. Hence, the standard deviation of velocity data obtained using broadband ADCPs are significantly lower than that for narrow band ADCPs in most cases. Figure 2.2 shows a contour of the velocity magnitude in a river cross section measured using a broadband ADCP.

The accuracy of the ADCP in predicting velocity has been benchmarked against standard stream gauging techniques (e.g., current meter, ADV, towing basin), and most results show agreement within 5\% (Shih et al. 2000; Oberg 2002; Mueller 2003; Oberg \& Mueller 2007; Gunawan et al. 2008). ADCPs have been used to characterize mean velocity and turbulence intensity in rivers (Lemmin \& Rolland 1997; Barua \& Rahman 1998; Muste et al. 2004a; Muste et al. 2004b; Le Coz et al. 2007; Stone and Hotchkiss 2007; Gunawan et al. 2010a), oceans/tidal channels (Lohrmann et al. 1990; Stacey et al. 1999; Cheng et al. 2000; Luznik et al. 2007; Epler et al. 2010; Thomson et al. 2010) and laboratories (Nystrom et al. 2007). ADCPs have also been used for measuring secondary current (Dinehart \& Burau 2005a; Szupiany et al. 2007; Gunawan et al. 2010b; Gunawan et al. 2010b), bed shear stress (Rennie et al. 2002; Rennie \& Church 2007; Sime et al. 2007), dispersion coefficient (Carr \& Rehmann 2007), sediment transports (Holmes \& Garcia 2002; Dinehart \& Burau 2005b; Merckelbach 2006; Klein 2003) and tidal flux (Turnipseed 2002).

Despite its extensive use, ADCP data may contain errors. One of the most noticeable errors is the large fluctuation in the single-ping ADCP data (single ADCP data output), which consist of a mix between turbulent fluctuation and random error. For example, Muste et al. (2004a) reported multiple velocity fluctuations as large as $45 \%$ on ADCP single velocity data output. Averaging multiple single-ping data reduces the fluctuation. Figure 2.3a illustrates the variation of the mean streamwise velocity for averaging periods of 1 second (single-ping data), 180 seconds and 300 seconds. After averaging for a certain period of time, the velocity fluctuation becomes smaller than the instrument bias. Hence, further averaging will not significantly change the mean velocity, as shown in the example for the streamwise velocity profile with 180 and 300s averaging. The required averaging time/number of samples to obtain stable mean velocity can be determined by plotting the averaging time versus the variation of mean velocity with respect to the averaging time. An example illustrated in Figure 2.3b shows that the depth-averaged streamwise velocity $\left(U_{d}\right)$ and the standard deviation $(\sigma)$ of the data in Figure 2.3a become stable after averaging for $\sim 180$ s.

Other errors, such as those caused by Doppler noise, velocity ambiguity, non-homogeneity of the flow, side lobe interference and transducers ringing, may significantly affect the accuracy of 
ADCP data. Hence, while obtaining the data using an ADCP is relatively easy, an additional level of post-processing should be applied in order to yield information pertaining to reliable velocity statistics. The ORNL ADCP data post-processing code currently being developed will be suitable for post-processing ADCP data obtained from stationary and moving boat measurements.
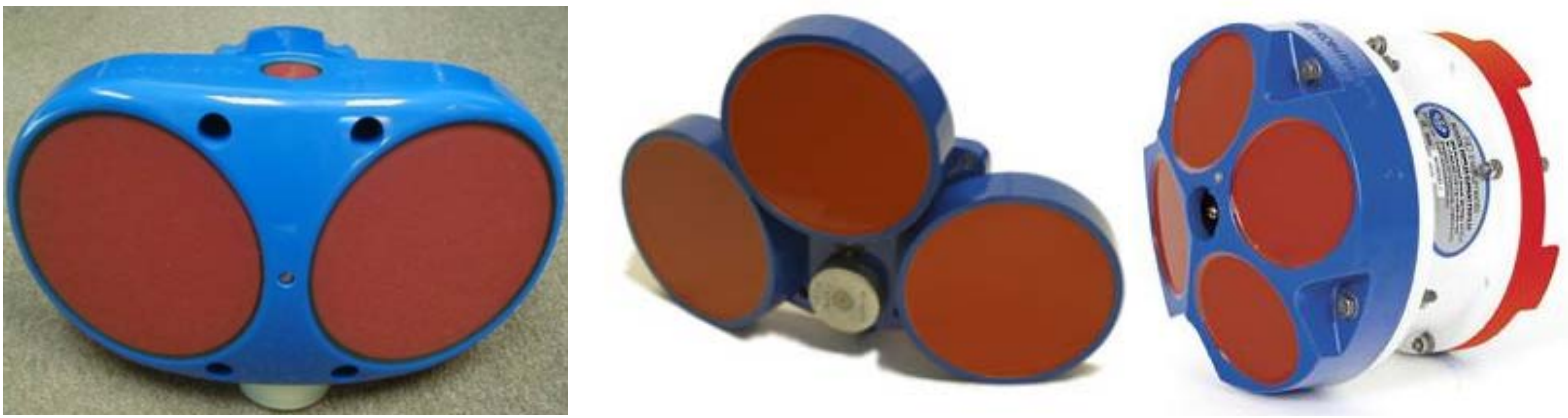

Figure 2.1 Different types of ADCP beam configurations (RDI 2011a).

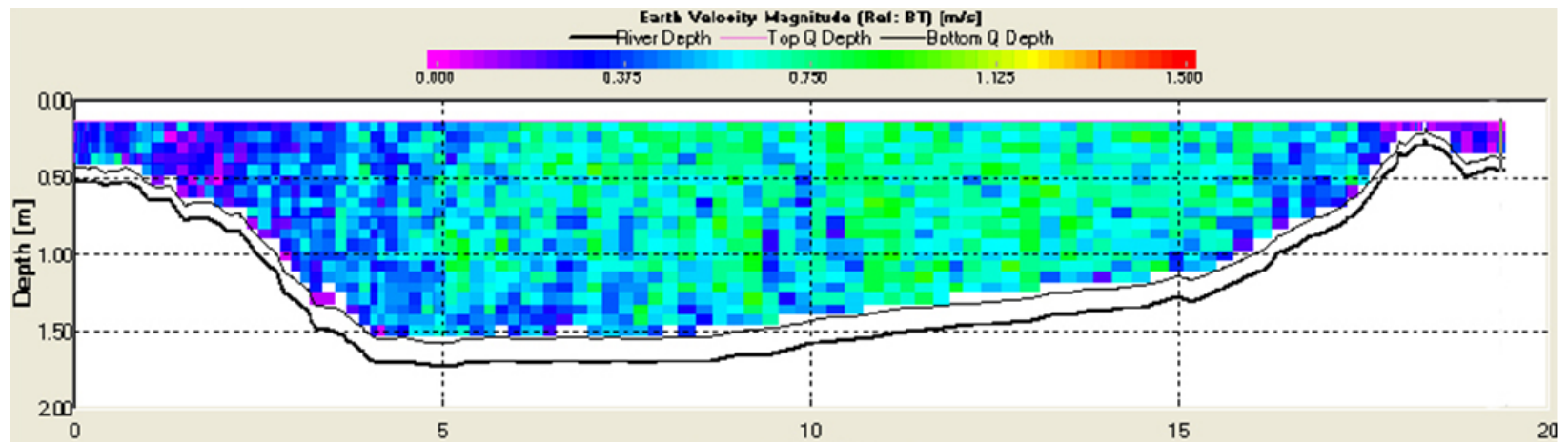

Figure 2.2 Contour of velocity magnitude in a river cross section measured using an RDI Rio Grande broadband ADCP (Gunawan 2010).

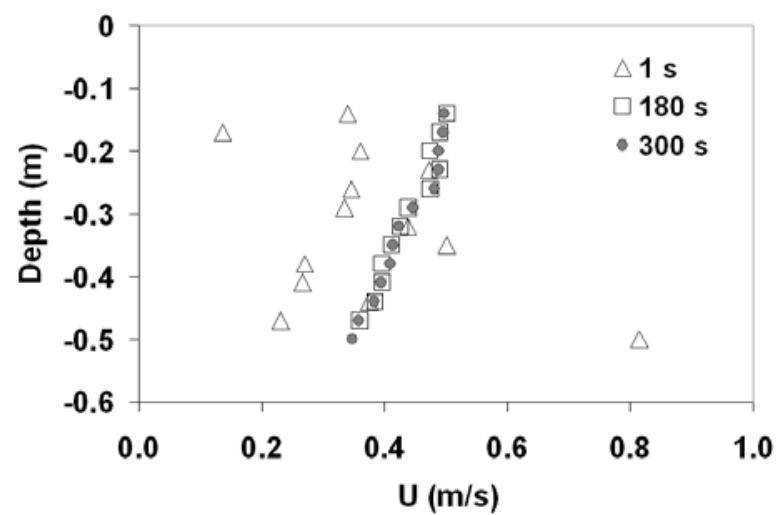

(a) Distribution of streamwise velocity profile for three different averaging times.

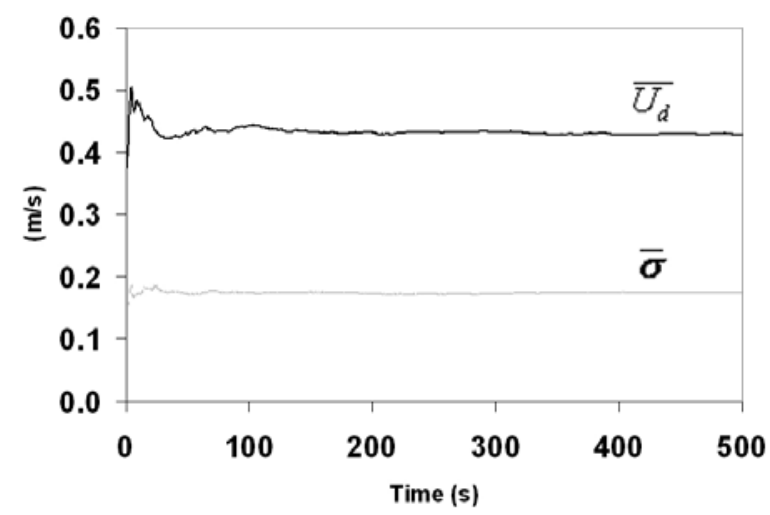

(b)Variation of depth-averaged streamwise velocity and standard deviation with respect to averaging period.

Figure 2.3 Variation of the streamwise velocity and standard deviation corresponding to a set of stationary measurements in a river (Gunawan et al. 2010a). 


\subsection{ADCP PRINCIPLE OF OPERATION}

An ADCP measures the movement of particles in the water relative to the ADCP position. As most of the particles in the water are small, it can be assumed that the velocity of the particles is the same as the velocity of the water. Most applications require the velocity of the water relative to a known reference, such as the earth coordinate system or the bottom boundary. This is not an issue if the ADCP is mounted in a fixed platform, such as river or sea bed. If the ADCP is deployed from a moving platform, such as a moving ship, the position of the ADCP at all times during the measurement has to be known. The ADCP bottom tracking capability or a GPS is typically used for such a purpose. When the position of the ADCP with respect to measurement time is known, the water velocity relative to the reference can be calculated by superimposing the velocity of the particles relatively to the ADCP position and the velocity of the ADCP instrument relative to the reference.

\subsubsection{Doppler shift principle}

The narrow band ADCPs measure the difference in frequency between the sound pulses emitted by the ADCP transducers and those reflected by particles in the water and received by the ADCP receivers. The Doppler principle can be described using the water-wave analogy. A stationary

observer (

Figure 2.4a) is watching a series of waves passing at a rate of one wave per second. When moving towards the source of the wave at four waves per second (

Figure 2.4b), the observer perceives the passage of five waves during every second, even though the frequency at which the waves are emitted has not changed (i.e., $1 \mathrm{~Hz}$ ). The difference in the perceived and transmitted frequency is called the Doppler shift, which can be expressed mathematically as:

where:

$$
\frac{F_{D}}{V_{S O}}=\frac{F_{S}}{C}
$$

$F_{D}=$ Doppler shift frequency $(\mathrm{Hz})$

$F_{S}=$ frequency of the transmitted sound $(\mathrm{Hz})$

$V_{S O}=$ relative velocity between the sound source and the observer $\left(\mathrm{ms}^{-1}\right)$

$C=$ speed of sound $\left(\mathrm{ms}^{-1}\right)$

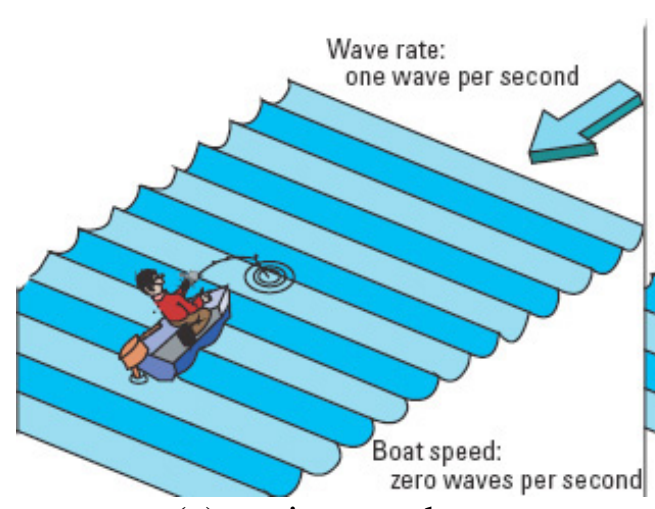

(a) stationary observer

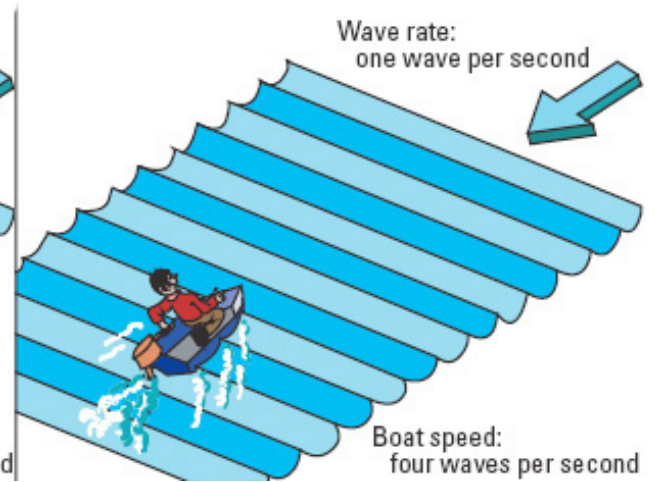

(b) moving observer 
Figure 2.4 The Doppler principle and a water-wave analogy (Simpson 2001).

ADCP transducers emit sound waves with a known frequency and velocity through water (Figure 2.5). Some portion of the emitted sound is reflected back to the ADCP (backscatter) by particles in the water. The frequency of the backscatters are shifted twice, the first Doppler shift is perceived by the particle when sound waves move toward the moving particle; while the second Doppler Shift is perceived by the transducers when sound waves are reflected back to the transducers by the particle (Figure 2.6). Hence, Equation (2.1) becomes:

$$
\frac{F_{D}}{V_{S O}}=\frac{2 F_{S}}{C}
$$

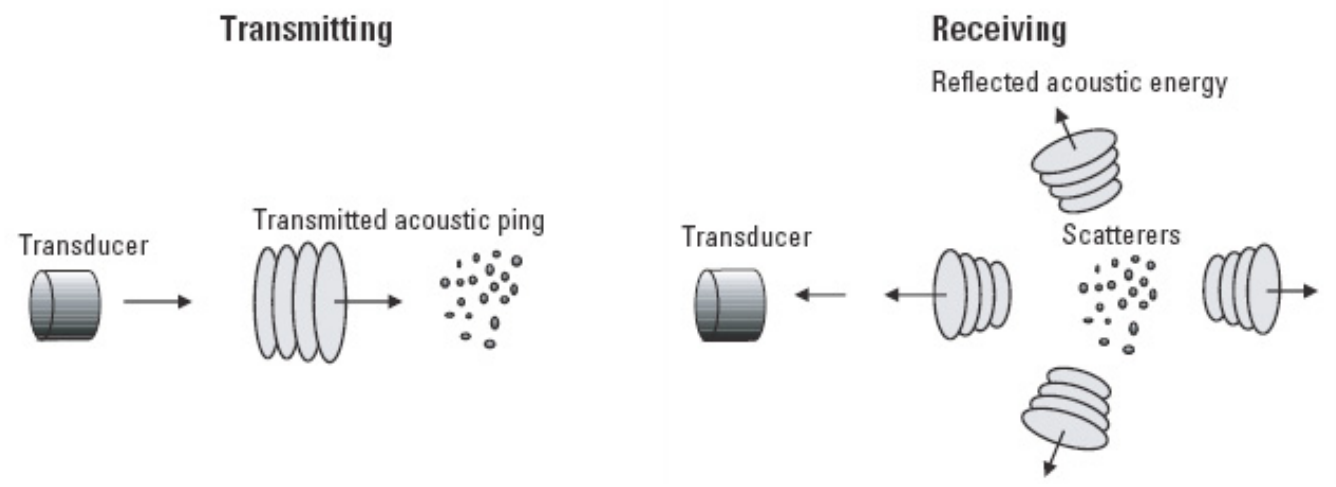

Figure 2.5 Sound wave transmission and reflection by particles (Simpson 2001).

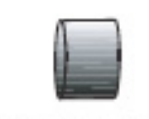

Transducer
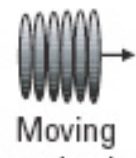

sound pulse

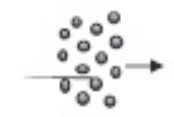

Moving

backscatterers
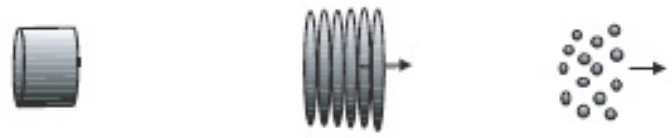

First Doppler shift (as perceived by scatterers)
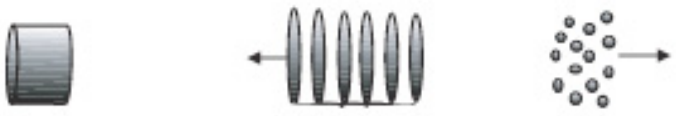

Second Doppler shift (as perceived by transducer)

Figure 2.6 Reflected pulse shows two Doppler shifts (Simpson 2001).

The Doppler shift occurs only when the particle has an angular motion with respect to the transducer, since the distance between the transducer and the particle will remain constant. Furthermore, only the velocity component along the acoustic beam is measured. Hence, when the particle is not moving along the beam (Figure 2.7), Equation (2.2) becomes: 


$$
\frac{F_{D}}{V_{S O}}=\frac{2 F_{S} \cos (\alpha)}{C}
$$

where $\alpha$ is the angle between the velocity vector and the transducer beam.

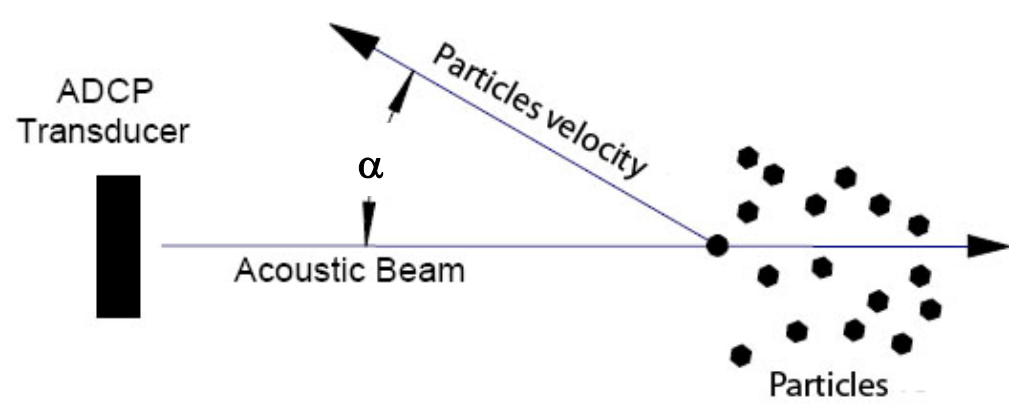

Figure 2.7 Transformation of velocity component into beam coordinate system (RDI 1996).

\subsubsection{The broadband ADCP}

The term broadband is used because the bandwidth of the ADCP was increased to accommodate the signal processing of a narrow-pulse pair (Muller and Wagner 2009). As bandwidth is synonymous with sampling rate, the number of samples taken per depth cell (bin) by a single ping increases if the bandwidth is increased. More samples in a single ping help reduce the single-ping standard deviation of velocity. The broadband ADCPs obtained hundreds of samples per ping, while only a few are obtained for the narrowband ADCPs (RDI 2011b). Figure 2.8 illustrates the difference between the narrow band and broadband ADCP pulses. The narrowband pulses are monochromatic, while the broadband pulses consist of many code elements having a phase shift of either a 0-degree or 180-degree system arranged in a pseudorandom order and having some lags. The broadband ADCP measures velocity using a different approach from the narrow band ADCP in a way that it measures the phase difference between the emitted sinusoidal pulses and their echoes to calculate the Doppler Shift, instead of using the frequency shift between the pulses. ADCP data are typically output for each single ping, the entirety of the sound generated by an ADCP transducer for a single measurement cycle (RDI 2011b).

The broadband ADCPs use the autocorrelation method to compare echoes from the same bin. An ADCP transmits a series of coded pulses and lags within a single long pulse, and receives numerous echoes from many sound scatterers from the same bin, all combined into a single echo. A high correlation value indicates the similarity of the echoes. The autocorrelation function is also used to compute the propagation delay, the change of travel time caused by the changing of the distance travelled by the pulses. 
Narrowband Monochromatic Acoustic Pulse

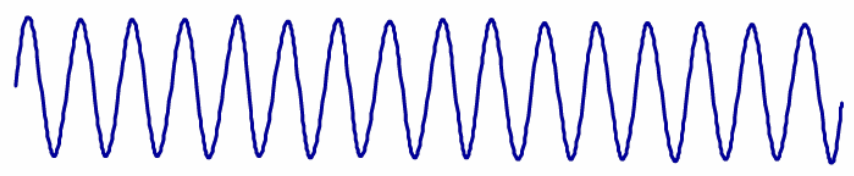

Broadband Coded Acoustic Pulse

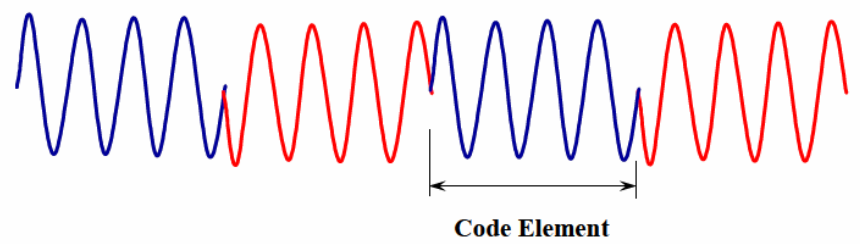

Figure 2.8 Acoustic pulses of narrow band and broadband ADCP technologies (Muller and Wagner 2009).

\subsubsection{Bin depth computation}

The velocity contour shown in Figure 2.2 consists of a set of over-depth velocity profiles along the river width. Each velocity profile consists of velocity data from different depth cells (bins). The broadband ADCP uses range gating to break the received signal into successive segments for independent processing, for each bin. According to the time dilation principle, as echoes from far ranges take longer to return to the ADCP than do echoes from close ranges, successive range gates correspond to echoes from increasingly distant depth cells. This principle can be explained using Figure 2.9. A transmitted broadband ping consists of only two code elements, both having a period of $1 / f_{s}$, with element $\mathrm{A}$ and $\mathrm{B}$ having a phase difference of 180 degrees (Figure 2.9a). The echoes from two stationary particles separated by a distance of $\Delta x$ are received at different times by the transducer, with a lag of $2 \Delta x / C$ second (Figure $2.9 \mathrm{~b}$ ). Since the particles stay stationary, the echoes keep their original shape, i.e., the period of the transmitted pulses are the same as that for the echoes.

a)

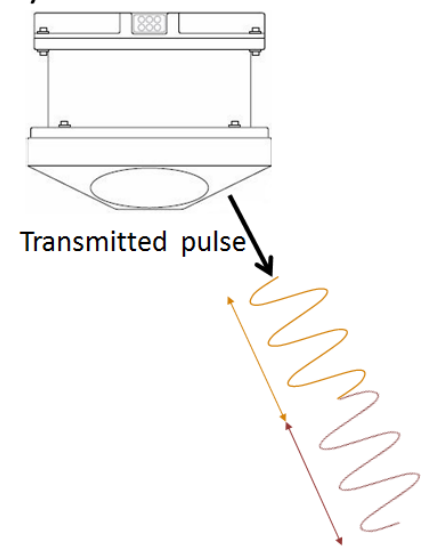

b)

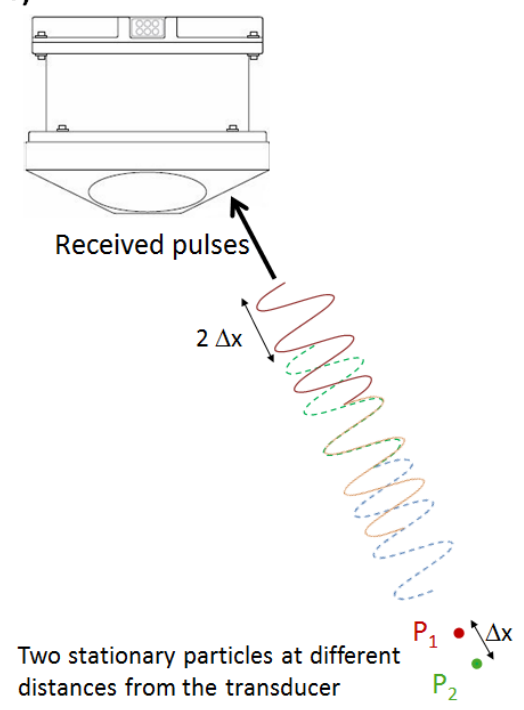

Figure 2.9 Time dilation principle 


\subsubsection{Transformation from beam to orthogonal coordinate system}

An ADCP requires at least three beam velocity components to construct the three-dimensional (3D) velocity in the orthogonal coordinate system. For the commonly used four-beam ADCPs, each pair of beams measures one horizontal velocity component and one vertical velocity component (Figure 2.10). For example, the East-West beams produce an East-West horizontal velocity and a vertical velocity; while the North-South beams produce a North-South horizontal velocity and a second vertical velocity (

Figure 2.11). The 3D velocity is the resultant of the East-West horizontal velocity, the NorthSouth horizontal velocity and one of the vertical velocities. The surplus in the vertical velocity component can be used to calculate an error velocity, the difference between the two vertical velocity components, which indicates the homogeneity of the velocity in a horizontal layer. Even though the homogeneity assumption is violated for resolving a $3 \mathrm{D}$ velocity vector, the $1 \mathrm{D}$ velocity profiles collected along each beam are still valid measurements. A detailed description of the coordinate transformation can be found in RDI (1998).

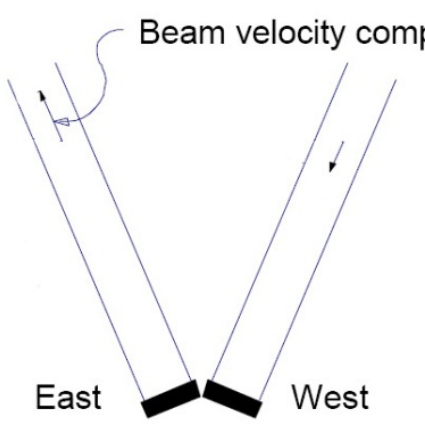

First pair of beams calculates east-west and vertical velocity

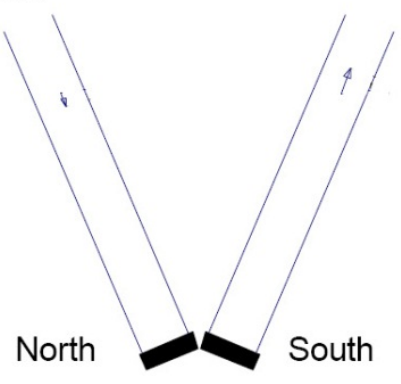

Second pair of beams calculates north-south and vertical velocity

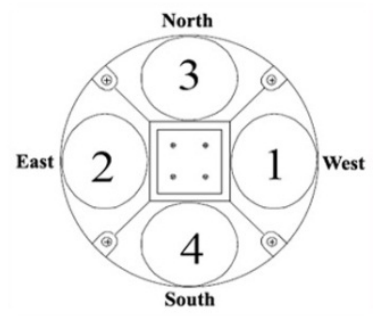

Figure 2.10 Beam velocity components (RDI, 1996).
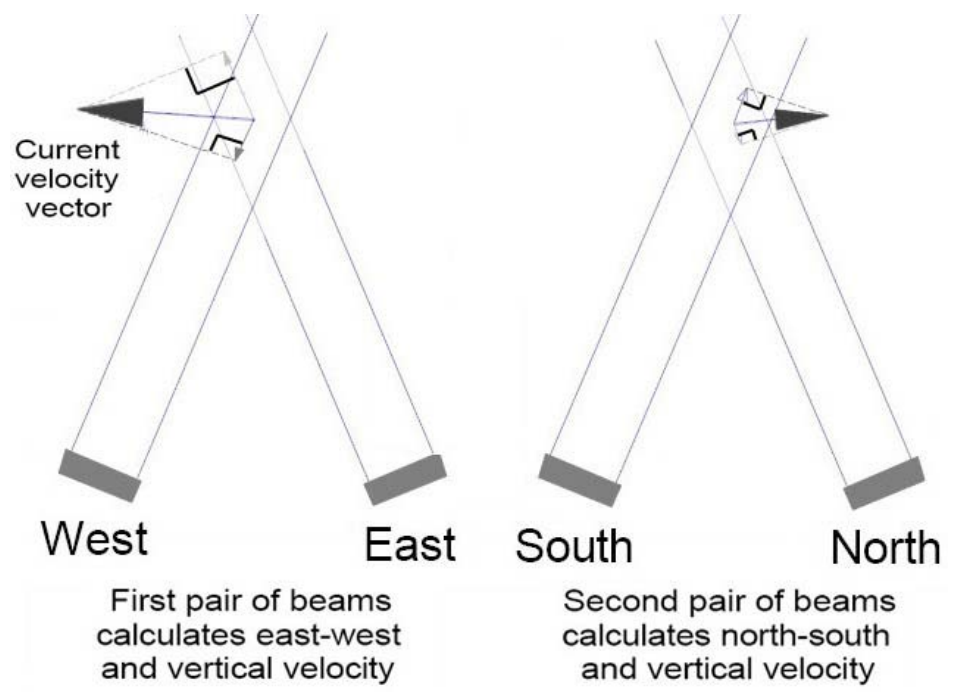

Figure 2.11 Velocity magnitude and direction in the E-W and N-S axis (RDI, 1996). 


\subsubsection{Bottom tracking}

Bottom-tracking pings are used to measure the bottom depth and ADCP boat velocity relative to the bed. The bottom-tracking pings have a lower frequency (longer pulse) than the water velocity profiling pings in order to properly illuminate the bed. The concept of the bottom depth and boat velocity measurements is similar to the one for the water profiling. Here, the particles are replaced by the river bottom. The boat velocity is also measured using the Doppler shift concept, but this time the boat is moving while the river bottom is standing still. Knowing the boat velocity and movement time, the boat path can be computed. As the water velocity relative to the ADCP and the velocity of the ADCP relative to the river bottom are known, the water velocity relative to the bottom can be calculated.

\subsection{ADCP MEASUREMENT AND DEPLOYMENT METHODS}

Common ADCP deployment methods include mooring and riverbed/seabed mounted for stationary measurements, as shown in Figure 2.12. The stationary measurements refer to fixing the ADCP at a location to sample the data at a period of time. This method provides accurate mean velocity data when some samples are averaged over a long period, and can be used to monitor water level changes. Another type of measurement is the ADCP moving-boat measurement. For this type of measurement, the ADCP is mounted on an underwater vehicle (Figure 2.12c), a remote-controlled boat (Figure 2.12d) or a large ship (Figure 2.13). Then, the ADCP measures velocity data while the boat is moving. This method is suitable to obtain velocity data for a large region, such as for the tidal current resource assessment of a region. 


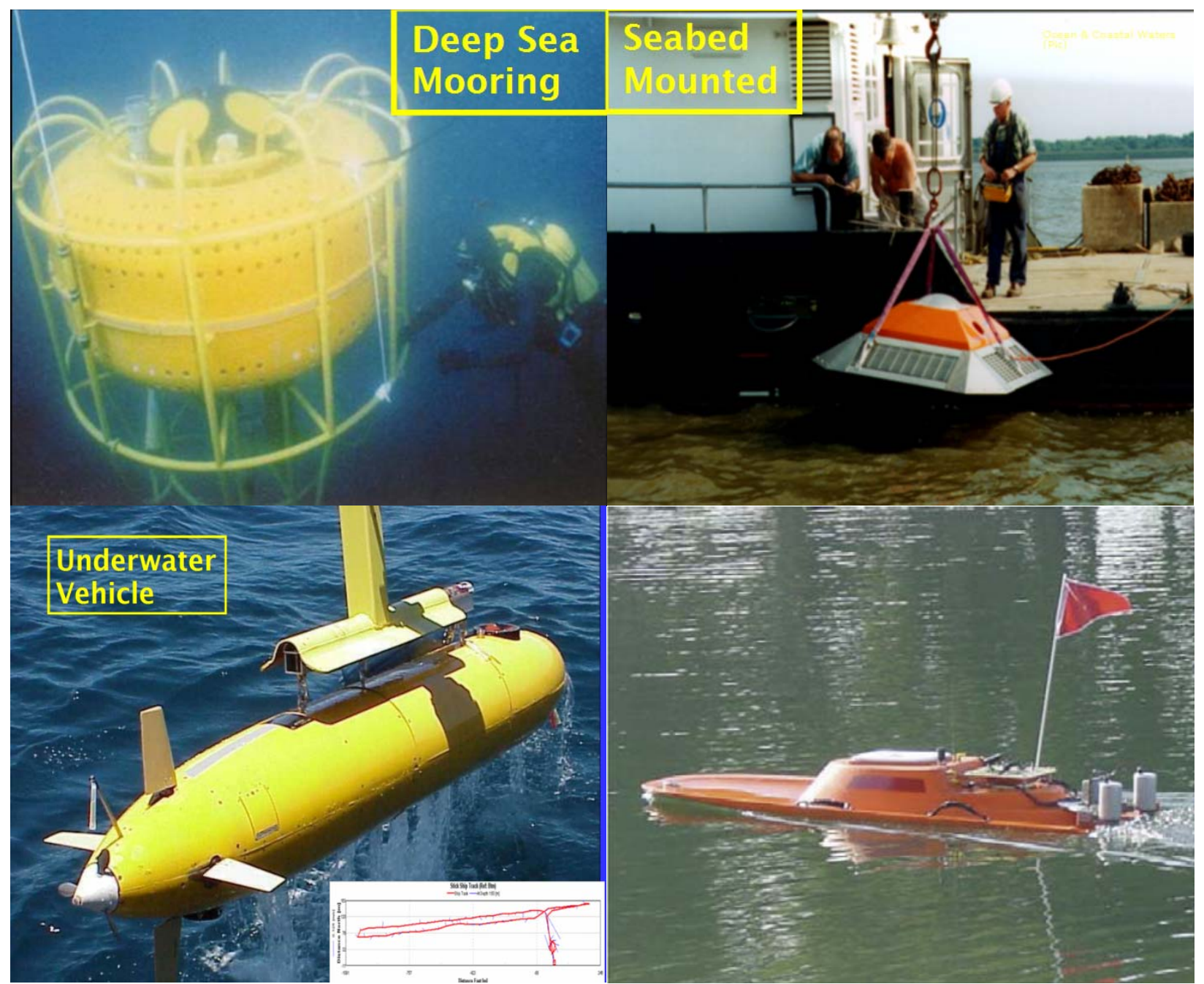

Figure 2.12 ADCP deployment methods: (a) mooring, (b) mounted, (c) underwater vehicle, (d) remote controlled boat (RDI 2011b; Muller and Wagner 2009).

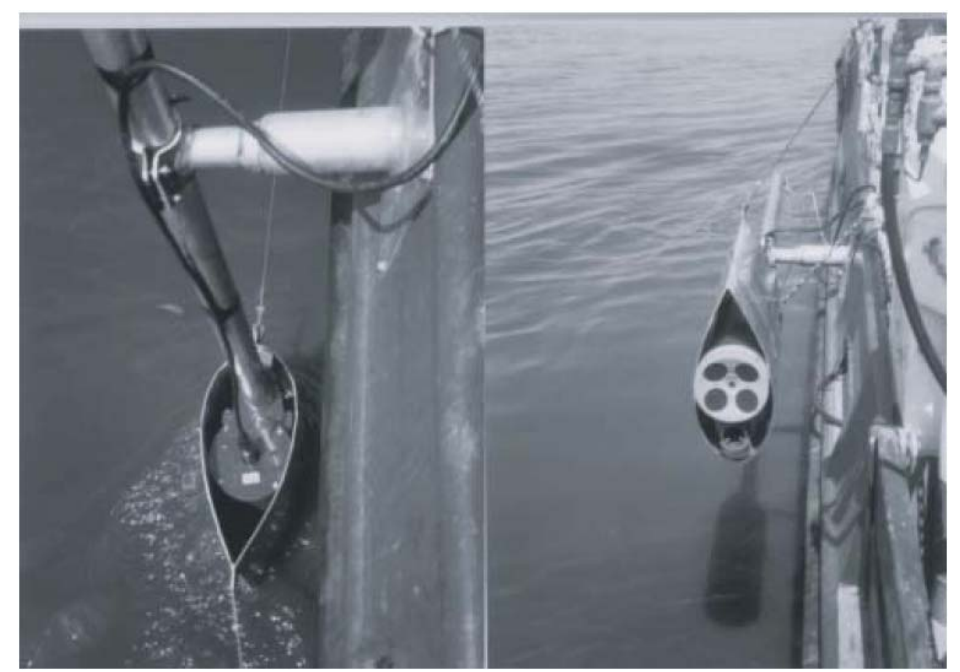

Figure 2.13 Two views of shipboard ADCP side-swing mount on a 30-meter (95-foot) vessel (Simpson 2001). 


\subsection{ADCP MEASUREMENT UNCERTAINTY}

ADCP velocity measurement uncertainty is caused by random error and bias (systematic error). Random errors depend on internal and external factors such as the ADCP frequency, depth cell size, number of pings averaged together, beam geometry, turbulence, internal waves and ADCP motion. Random errors can be reduced by averaging the data over a long period of time. The bias errors are influenced by several factors that include temperature, mean current speed, signalto-noise ratio (SNR) and beam geometry. Bias cannot be calibrated or removed, but its magnitude is typically less than $10 \mathrm{~mm} / \mathrm{s}$ (RDI 1996). Other errors, such as the presence of materials that obstruct the sound pulses transmission, can disturb the velocity measurements. Some of the causes of errors are described below.

\subsubsection{D velocity sampling volume}

The size of the 3D velocity measurement sampling volume can be expressed as the volume of a cylinder along the four beams with the bin size as its height (Figure 2.14). The 3D velocity sampling volume increases with increasing distance from the ADCP due to beam divergence. Large 3D velocity sampling volume increases the probability to have non-homogeneous horizontal velocities at all of the beams, which cause errors in the 3D velocity data. The 3D velocity sampling volume should not be confused with the individual beam sampling volume.
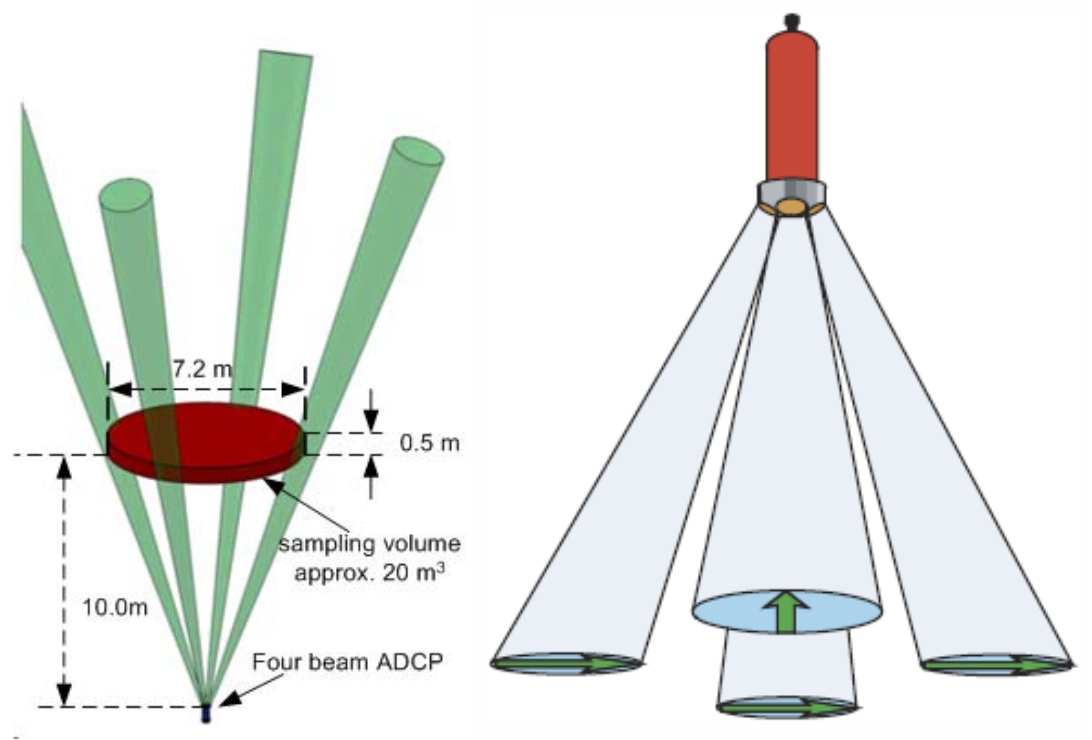

Figure 2.14 Left: schematic of a four-beam ADCP showing typical sampling volume (Neary et al. 2011a); right: non-homogeneous horizontal velocities (Simpson 2001).

\subsubsection{Beam sampling volume}

The size of the sampling volume in each beam is determined by the size of the bin used, which can be varied by users. A large measurement volume will spatially low-pass filter the velocity field and may bias the statistics away from small-scale structures that may be important for unsteady loading and system vibration and noise. On the other hand, a small measurement volume contains more noise. These factors should be taken into consideration when choosing the bin size to be used in the deployment setting. 


\subsubsection{Echo attenuation}

Echo intensity $(E I)$ is a measure of signal strength of the echo returned to the ADCP. When the level of echo intensity drops below the noise level of the instrument, the ADCP cannot accurately calculate Doppler Shifts; hence, this parameter governs the ADCP measurement range. $E I$ is affected by sound absorption in the water, beam spreading, transmitted power and backscatter coefficient. Their relation can be expressed as follows:

$E I=S L+S V+$ constant $-20 \log (R)-2 \beta R$

where:

$E I$ is the echo intensity (dB)

$S L$ is the source level or transmitted power (dB)

$S V$ is the water-mass volume backscattering strength $(\mathrm{dB})$

$\beta$ is the absorption coefficient $(\mathrm{dB} / \mathrm{m})$

$R$ is the distance from the transducer to the depth cell (m)

$E I$ is a relative parameter in the sense that the ADCP can detect variations in $E I$, but cannot make absolute measurements that can be compared with other ADCPs. The constant is included because the measurement is relative rather than absolute. A high concentration of scatterers corresponds to the higher $E I$ rather than in a low concentration of scatterers because more sounds are reflected by the scatterers. Sound pulses spread as a function of distance from the transducers once they are transmitted. Hence, the intensity of the echoes received by the transducer also decreases with the distance from the transducer. Sound absorption by the water reduces the strength of the echoes and is affected by the physical and chemical processes in the water.

\subsubsection{Lack of scatterers}

Velocity data cannot be measured when sound scatterers do not exist in the water column. The amount of suspended sediments in rivers is generally sufficient to produce strong echoes. In an ocean environment, lack of scatterers at a certain depth is not uncommon. For example, on a cruise near Mauritius only one-third of the nominal range contain velocity data, and this kind of condition is occurring less than $10 \%$ of the time (RDI 1996).

\subsubsection{Side lobe interference}

Due to some technical limitations, instead of only transmitting sound pulses through the main lobe (main beam), the ADCP also transmits sounds through the side lobes, but at a lower intensity than the sound transmitted through the main lobe. The angle between the main lobe and the side lobe is typically around $30-40^{\circ}$. The returning echoes from the side lobe sound reflected by the hard surface, such as ocean bed or water surface, have a similar intensity as the returning echoes from the main lobe sound reflected by the particles in the water. For a $20^{\circ}$ beam angle ADCP deployed upward looking, the echoes from the side lobe sound reflected by the water surface are received by the transducers at the same time as the echoes from the main lobe sound reflected by the particles in the water at $94 \%$ of the ADCP distance to the surface (RDI 1996). The ADCP data are contaminated from this distance onwards to the water surface. 
Whereas, an ADCP manufacturer reports that 94\% of the ADCP distance to the surface is the threshold for side lobe interference, other researchers have experienced threshold values less than that (e.g., Gunawan et al. 2010). Figure 2.15 shows a contour of velocity magnitude obtained using an upward looking ADCP; the side lobe interference can be clearly seen at bin \#61 and the adjacent region.

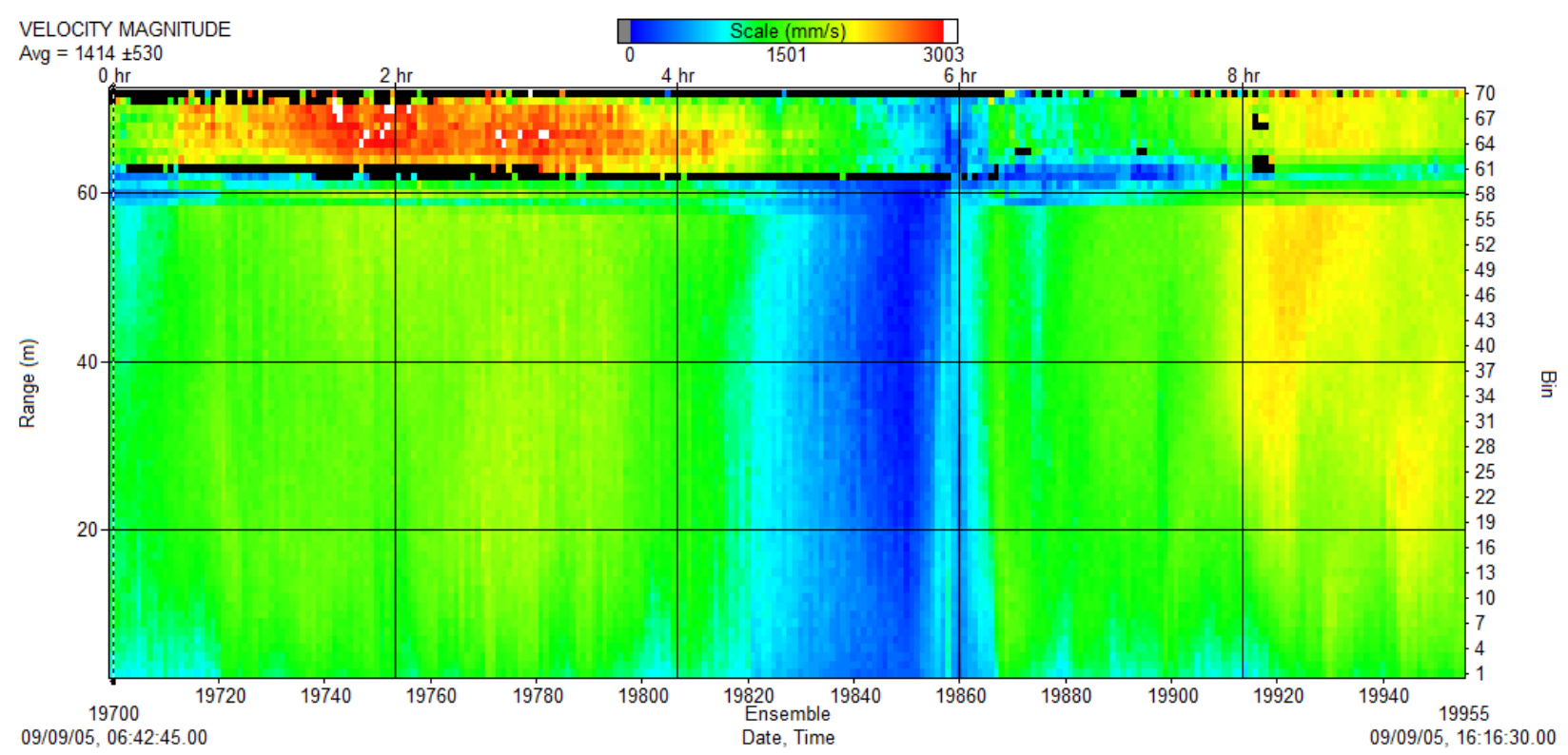

Figure 2.15 Contours of velocity magnitude at a location in Puget Sound, WA, obtained from an upward looking ADCP (courtesy of the Northwest National Marine Renewable Energy Center, University of Washington).

\subsubsection{Transducers ringing}

The ADCP cannot measure velocity in a small region adjacent to the transducers due to transducer ringing. ADCP transducers vibrate for a while after transmitting sound pulses and, during this time, the returned echoes are contaminated by the vibration (ringing). The time required until the ringing dissipates, often referred to as the blanking period, corresponds to the distance of the first bin from the transducers that can be measured by the ADCP. The typical blanking distance for a $300 \mathrm{kHz}$ and a $1200 \mathrm{kHz}$ RDI ADCP is $2 \mathrm{~m}$ and $0.5 \mathrm{~m}$, respectively (RDI 1996).

\subsubsection{Ambiguity}

Phase shift can only be measured in the range of $0^{\circ}-360^{\circ}$. Hence, the measurement will start again from $0^{\circ}$ once the phase passes $360^{\circ}$. In this case, an abrupt change in the velocity (a spike) is likely to occur (Figure 2-6). A change of sign occurs when the phase shift exceeds $360^{\circ}$ but is still below $720^{\circ}$. No change of sign occurs when the phase shift exceeds $720^{\circ}$ but is still below $1080^{\circ}$. In order to overcome this issue, prior to deployment and data collection, the ADCP user must specify the maximum velocity expected to be sampled in the flow (the ambiguity velocity). The ambiguity velocity is the maximum allowable radial motion for phase measurements to be unambiguous. 


\subsubsection{Moving-bed condition}

ADCP bottom track or GPS data is required to take into account the movement of the ADCP when calculating water velocity. The ADCP bottom track fails if high amounts of material, such as clay or sand, are moving near the bed. Such a condition typically happens in rivers during high flow; whereas, high velocity causes the river bed to be eroded. A moving bed condition can be detected by examining the ADCP stationary measurement data. Significant movements of the ADCP shown in the data indicate that moving bed condition is likely to happen.

\subsubsection{The presence of submerged vegetation}

The presence of vegetation can significantly inhibit the ability of the ADCP to give reliable measurements as the bottom tracking is disrupted (Gunawan et al. 2010). This is perhaps not too surprising if one considers the principle of operation. Vegetation near the channel bed has the propensity to disrupt the bottom tracking and also to cause anomalous velocity measurements.

\subsubsection{Air bubbles}

Breaking waves generate bubbles below the ocean surface. Passing under the ship's hull, the bubbles can act as a shield that distracts the transmission of sound pulses. They can reduce the ADCP profiling range and, in the worst case, completely block the sound transmission.

\subsection{PROTOCOLS FOR REDUCING ERROR}

Errors in the ADCP velocity data can be reduced using several methods outlined below.

\subsubsection{Temporal averaging}

One method often used to reduce the velocity fluctuations is to average the velocity data over a reasonably long period of time (e.g., 3 to 15 minutes). However, this method is only suitable for a stationary ADCP measurement since the measurement location does not change with respect to time when this deployment method is used. After averaging for a certain period of time, the mean velocity becomes statistically stable, i.e., it does not change significantly with more samples to be averaged. The averaging time to obtain stable mean streamwise velocity in rivers depends on many variables, such as the flow characteristics of the site and bin size; but is typically less than 15 minutes. A summary of the suggested averaging time by different researchers is presented in 
Table 2.1. Gunawan (2010) reported that out of 31 stationary measurements undertaken at two river cross sections, 30 satisfied the $5 \%$ convergence level for the mean streamwise velocity when averaged over 300s. The 5\% convergence level indicates that the difference between the mean streamwise velocity averaged over 300 s and the last 20 samples is less than $5 \%$. Knowledge of the minimum averaging time is beneficial, especially when conducting a stationary measurement using a boat-mounted ADCP (the boat position is fixed during the measurement). Using the minimum averaging time ensures that adequate accuracy on the mean velocity profile is achieved within the shortest measurement time possible. 
Table 2.1 Minimum averaging time for ADCP stationary measurement in rivers suggested by different researchers.

\begin{tabular}{|c|c|c|c|c|}
\hline Source & $\begin{array}{c}\text { Barua \& Rahman } \\
\qquad(1998)\end{array}$ & $\begin{array}{l}\text { Stone \& Hotchkiss } \\
\qquad(2007)\end{array}$ & $\begin{array}{c}\text { Szupiany et al } \\
\text { (2007) }\end{array}$ & $\begin{array}{c}\text { Gunawan } \\
\text { (2010) }\end{array}$ \\
\hline Suggested averaging time & $900 \mathrm{~s}$ & $100-250 s$ & $420-600 s$ & $300 \mathrm{~s}$ \\
\hline River width & $\sim 11,000 \mathrm{~m}$ & $12.8-15.4 m$ & $600-2,500 m$ & $\sim 5-8 \mathrm{~m}$ \\
\hline $\begin{array}{l}\text { River depth } \\
\text { ADCP model }\end{array}$ & $\begin{array}{l}8.3-10 \mathrm{~m} \\
\text { RDI } \quad \text { Broadband } \\
\text { ADCP }\end{array}$ & $\begin{array}{l}0.75-1.1 \mathrm{~m} \\
1200 \mathrm{kHz} \text { RDI Broadband } \\
\text { Rio Grande ADCP }\end{array}$ & $\begin{array}{l}5-12 \mathrm{~m} \\
1000 \mathrm{kHz} \text { SonTek } \\
\text { ADP }\end{array}$ & $\begin{array}{l}\sim 0.6-1.2 \mathrm{~m} \\
\text { 2MHz RDI Broadband } \\
\text { StreamPro ADCP }\end{array}$ \\
\hline Sampling frequency & $0.5 \mathrm{~Hz}$ & $\sim 1 \mathrm{~Hz}$ & $12 \mathrm{~Hz}$ & $1 \mathrm{~Hz}$ \\
\hline Bin size & $50 \mathrm{~cm}$ & $5 \mathrm{~cm}$ & $50-75 \mathrm{~cm}$ & $5-10 \mathrm{~cm}$ \\
\hline Max. boat movement & $3 \mathrm{~m}$ & N/A & $5 \mathrm{~m}$ & $0.1 \mathrm{~m}$ \\
\hline
\end{tabular}

\subsubsection{Spatial averaging}

The ADCP stationary measurement is not suitable for measuring the mean velocity at many locations within a short time, as it is very time-consuming and costly. Moving-boat ADCP measurement reduces the measurement time significantly, but it has its own issue. As the ADCP (and the boat) is moving during the measurement, only one profile sample is obtained at every boat position. The number of samples is not sufficient for reducing the random error in the data. Spatial averaging helps reduce the random error in the data.

Obtaining velocity data at numerous locations is required for many purposes, such as to investigate the detailed flow structures in a river cross section and to assess the potential MHK energy resources in a tidal channel. The detailed flow structures in a river cross section are crucial to identify the best location to place the MHK devices and to investigate the coherent structures in the flow which cause extra structural loads and moments on the MHK devices. Coherent flow structures can be caused by the internal or external flow disturbance in the river. The internal disturbances include the helical secondary flow motion along the longitudinal direction caused by turbulence or centrifugal force (Einstein \& Li 1958; Perkins 1970) and the plan-form vortices due to the high velocity gradient typically occur during an overbank flow condition (Sellin 1964; Ikeda 2001; Knight et al. 2009). The external disturbance of the flow is caused by an external structure, such as the MHK device itself or a bridge pier. Figure 2.16 illustrates vortex shedding affecting an MHK turbine downstream of a cylinder structure. Apart from causing an extra load, coherent structures can potentially cause a resonance failure if the resonance frequency of a moving or vibrating component of the MHK device is the same as the frequency of the coherent structures.

A regional assessment of MHK energy resources potential requires a great number of data to be collected along a large region. ADCP moving-boat data can be used for this purpose; but, data post-processing, mainly to reduce the random errors and to extrapolate the data to the unmeasured region, should be performed. 


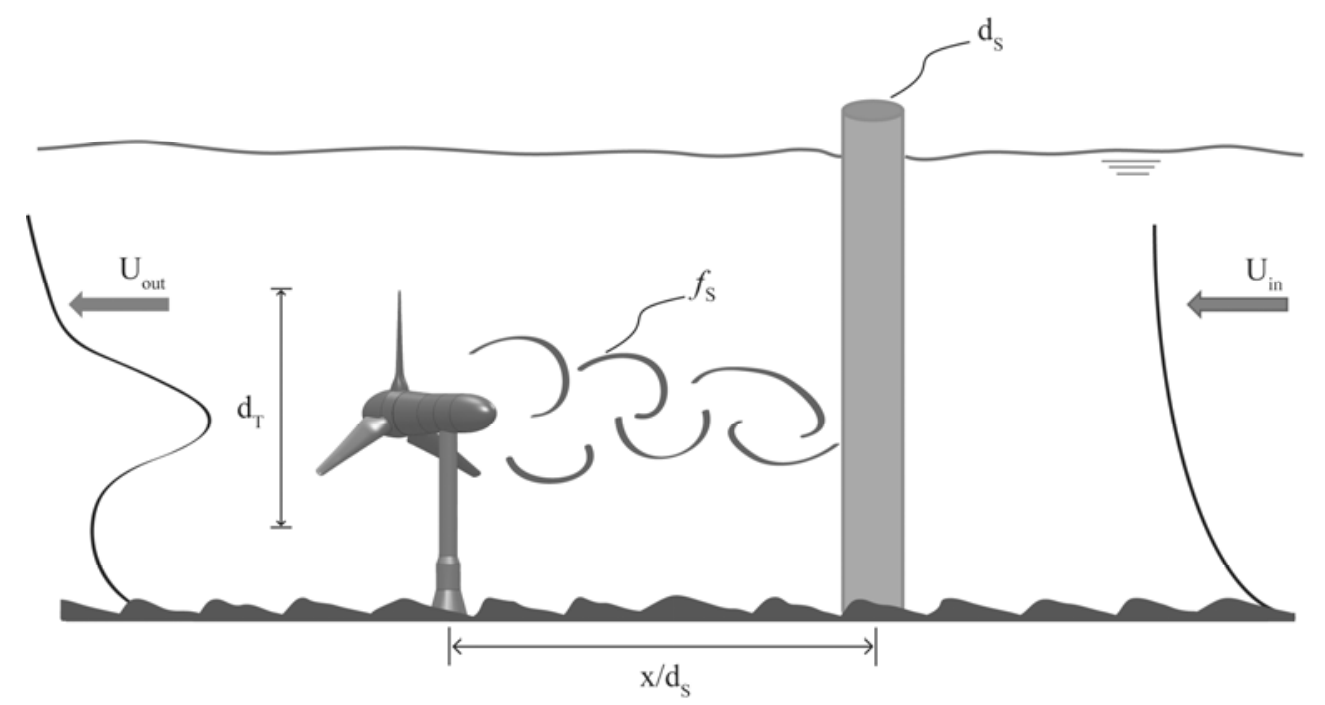

Figure 2.16 Conceptual layout with schematic of perturbed turbulent inflow approaching turbine (Neary et al. 2011a).

The detailed flow structures in a river cross section can be obtained by averaging several ADCP transects data together. The ADCP transect data are obtained by traversing the ADCP in a river cross section. Averaging several transects together reduces the data fluctuation due to random errors and turbulence, and helps to obtain a clearer pattern of the secondary flow circulation (Dinehart and Burau 2005; Szupiany et al. 2007; Gunawan et al. 2010b). An example of a transect averaging result is shown in Figure 2.17. One of the key points when conducting transect averaging is to ensure that the transect data are obtained at the same cross section.

Dinehart and Burau (2005) averaged the velocity data from each ADCP transect by interpolating them into a $2 \mathrm{D}$ grid representing the cross section of the corresponding measurement. The value at each node of the grid was calculated using an inverse distance weighting (IDW) method (six samples points were selected by an equipartite arrangement). Each set of the interpolation grids was averaged together to obtain the final velocity grid. Szupiany et al. (2007) used a SonTek ADP (Acoustic Doppler Profiler) to measure the 3D velocity in River Parana, Argentina, at several cross sections of 600-2400m widths. Szupiany et al. (2007) suggests that the finer detail of the existence of secondary flow cells can be obtained by averaging five transects. Le Coz et al. (2007) used the IDW method to average the ADCP transect data obtained from a 100m wide river. Their results suggest that the number of data points considered for calculating the IDW interpolation value at each node of the grid affects the smoothness of the velocity profiles in the IDW-interpolated grid. As a quality measure, Le Coz et al. (2007) report that the difference between the discharge in the river before and after the IDW interpolation is always within 3\%. Gunawan et al. (2010a) reported that the transect averaging results depend on the size of the interpolation grid and the distance between the measurement data point and the IDW interpolation node in the grid. When a data point is too close to the interpolation node, the velocity value at that data point has a dominant influence on the interpolated velocity at the node. If the data point close to the interpolation node is a spike, the IDW interpolation method will only have a minor effect in smoothing the spike. Gunawan (2010) conducted measurements in two river cross sections and compared the depth-averaged streamwise velocity of the ADCP transect averaging results and the time-averaged stationary ADCP data. An average difference 
of 3.4\% was reported (Figure 2.18).
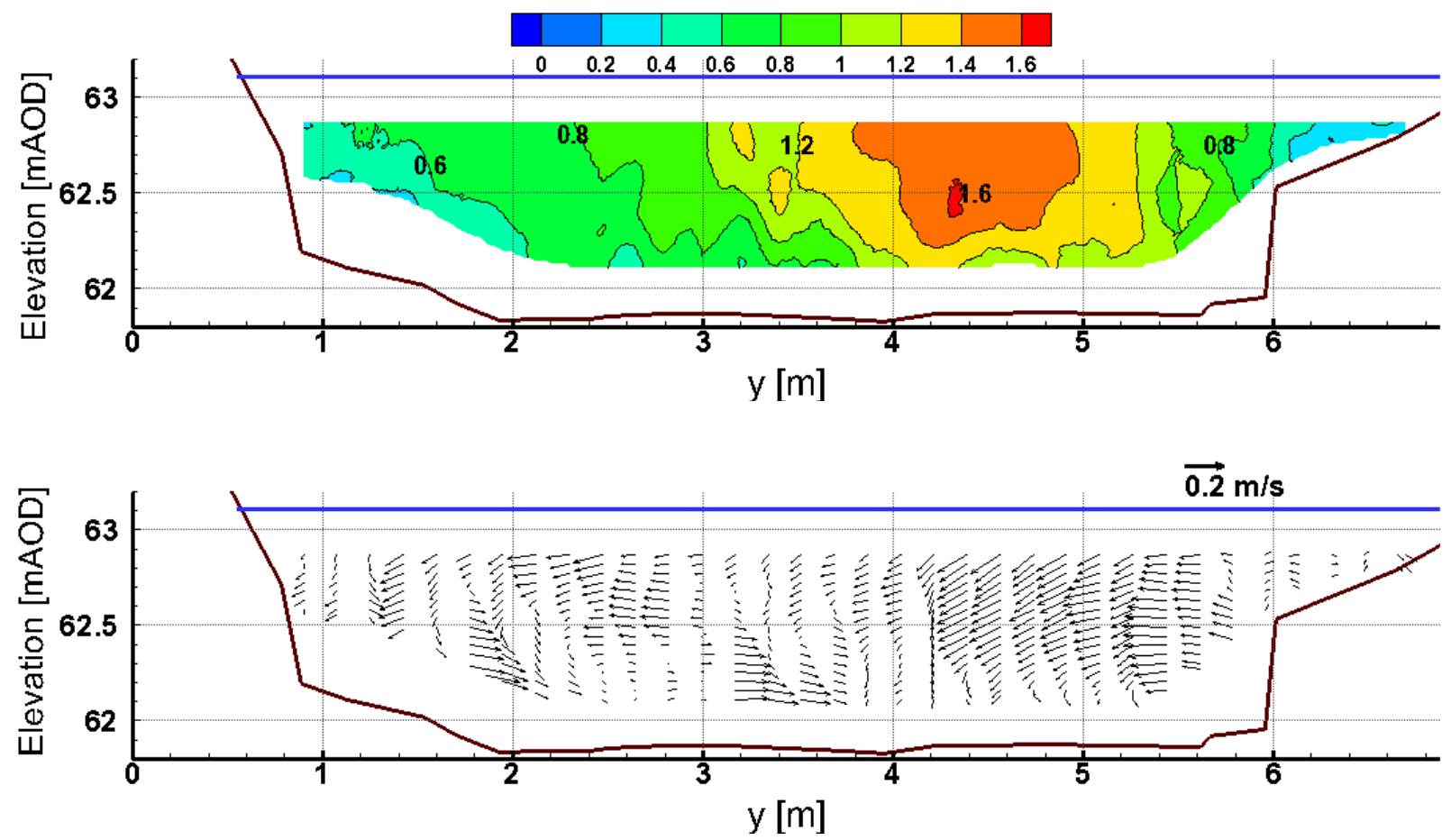

Figure 2.17 Results of ADCP transect averaging; top: contour of normalized streamwise velocity $(U / \bar{U})$, bottom: $V$ and $W$ velocity vectors (Gunawan 2010b).

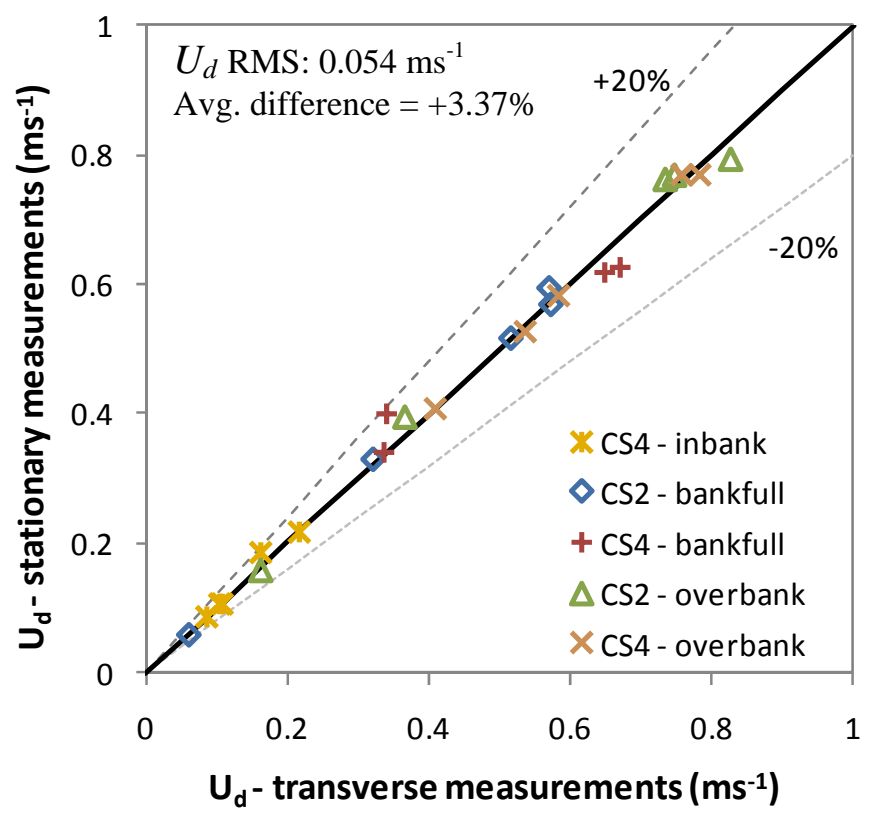

Figure 2.18 Difference between $U_{d}$ values obtained from ADCP stationary measurements and ADCP transect averaging results at two cross sections (Gunawan 2010). 


\subsubsection{Histogram inspection}

Effects of over-ranging on data are easy to identify. The probability density function (PDF) of a time series (in the beam coordinate system) may demonstrate a sudden velocity cut-off beyond which no data will be registered, which is often caused by the ambiguity problem. If this abrupt discontinuity is observed in a data sample, the user should attempt to increase the user defined velocity range until the histogram of the time series no longer demonstrate such characteristics. Optimally the user should select the smallest velocity range (in either beam or earth coordinates) for which no cut-off is observed in the histogram.

\subsubsection{Spike identification, removal and replacement}

Baldwin et al. (1993) and Petrie et al. (1988) first applied a velocity hodograph elliptical filtering technique to laser Doppler velocimeter (LDV) measurements as an effective means of filtering LDV measured noise. In this technique, the measured data are rotated into the principal stress coordinates and an elliptic filter of size $N$ principal stresses in the minor and major axes is applied to the 2D probability density function (PDF). Velocity ensembles occurring outside the defined ellipse are filtered from the data set. Fontaine et al. (1996) extended the 2D elliptic filter technique to the 3D flow application with a principal stress 3D ellipsoid filter on threecomponent LDV measured data.

The Phase-Space Thresholding (PST) technique, developed by Goring and Nikora (2002), is another ellipsoidal filter technique where invalid points are identified as those lying outside of the universal threshold defined ellipsoid in a 3D Poincaré phase space. While the ellipsoidal filter technique of Fontaine et al. (1996) operates on the instantaneous velocity hodograph ( $u$ vs $v$ vs $w$ ) with filtering applied in the principal stress space, the PST technique operates on the instantaneous velocity and it's local accelerations ( $u$ vs $d u / d t)$. The PST technique has been critically analyzed and improved upon by a number of peers (Pasheh et al. 2010; Wahl 2003).

The use of the PST algorithm has grown in acceptance and is now the standard means of filtering data. Nevertheless, improvements to the PST algorithm have been proposed to address the main criticism that it was replacing valid data around spikes. While removal has negligible effects on the value of bulk statistical moments, it has been shown by (Pasheh et al. 2010) to compromise time-dependent indicators such as the power and energy spectra. Goring and Nikora (2002) have suggested cubic interpolation by the twelve points on either side of an identified invalid datum and they seem to be one of the few researchers to have compared various methods. Pasheh et al. (2010) have proposed a modified Phase-Space-Thresholding Sample and Hold algorithm (mPST$\mathrm{SH})$ that evaluates the validity of data in three stages: first, any velocity measurements near the average are incontrovertibly marked as valid; then, any data far from the average are marked as invalid and are removed; finally, the data are filtered using the PST technique. 


\section{ORNL ADCP DATA POST-PROCESSING METHODOLOGY}

The current version of the ORNL ADCP data post-processing methodology is capable of detecting, removing and replacing invalid data (outliers) from the ADCP stationary data using the Phase-Space Thresholding (PST) and the modified Phase-Space Thresholding (mPST) methods. Three schemes of data replacement are available: replacement by the overall average, replacement by the previous valid point and replacement by polynomial interpolation. The ORNL ADCP data post-processing methodology also calculates the mean velocities, RMS velocities and Reynolds stresses at each velocity bin. The code to spatially average the ADCP transects data is currently under development and is expected to be publicly available in mid2012.

\subsection{ALGORITHM}

The algorithm of the ORNL ADCP data post-processing code is written in MATLAB and consists of several independent functions that are called by the main program (Figure 3.1). The ORNL ADCP data post-processing to post-process the ADCP stationary data is a modification of the ORNL ADV data post-processing code (Gunawan et al. 2011). The major difference lies in the data input; instead of using one velocity measurement or multiple point velocity measurements, all the bins along the ADCP measurement depths are used. The first step to run the code is to export the ADCP data into the MATLAB workspace. If the data are in Microsoft Excel-compatible format, such as *.csv, the MATLAB function xlsread would be convenient to use as it detects and removes the unused file headers. The user is then given the choice to implement Phase-Space Threshold (PST) filtering, modified Phase-Space Threshold (mPST) filtering or to bypass PST altogether. The outliers can be replaced by selecting from three replacement methods. The number of outliers is then computed and the user will be given the option to draw the velocity time series (3 velocity components) with the outliers marked with red circles. When the PST or mPST filter is chosen, the number of outliers is computed and the user will be given the option to plot the velocity time series and the ellipsoid that delineates the threshold for outliers. Once the filtering process is completed, the user is given the option to plot the velocity power spectra. The user inputs the sampling rate of the ADCP used during measurements if this option is chosen. 


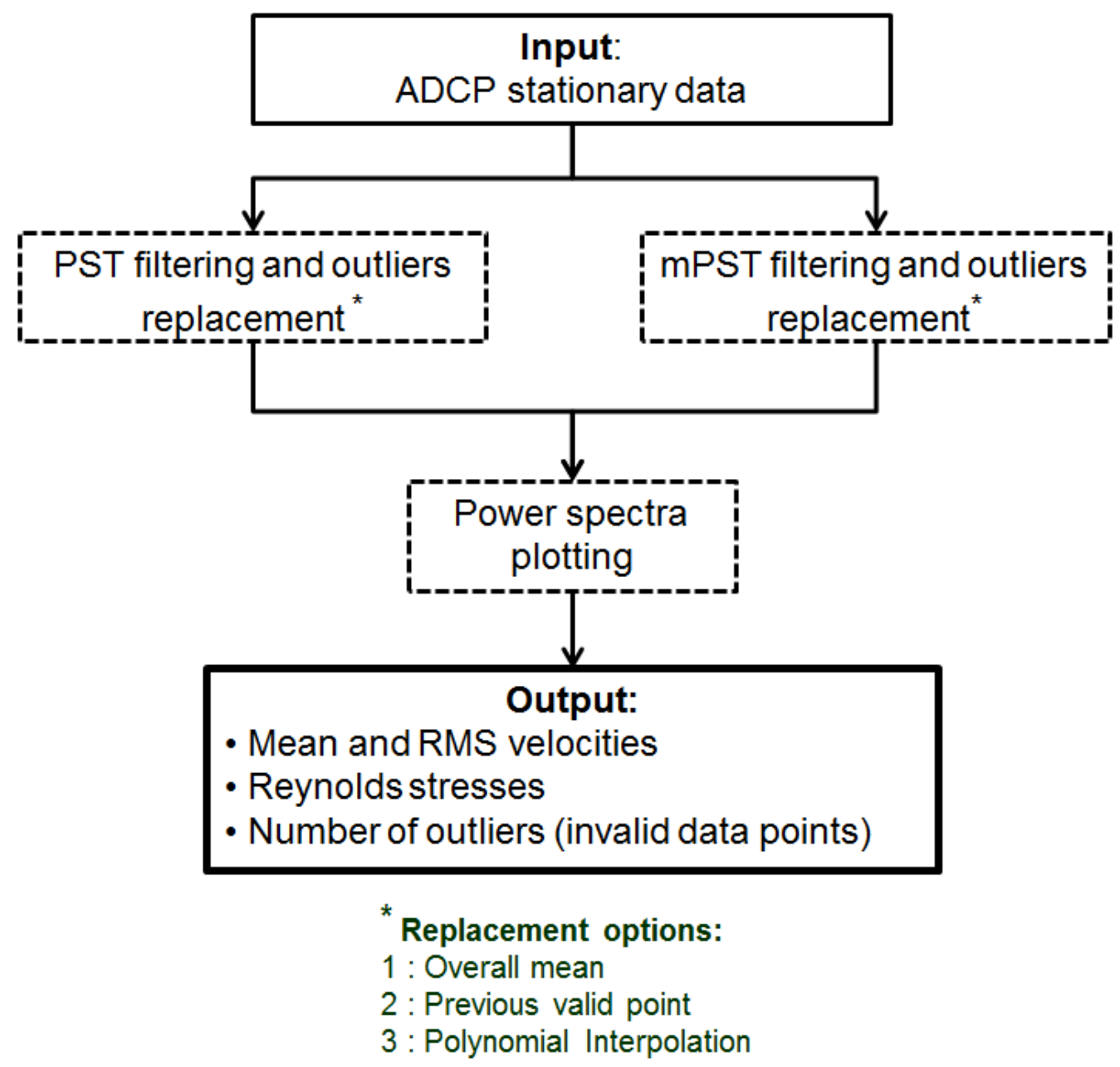

Figure 3.1 Algorithm adopted for the ORNL ADCP data post-processing methodology - the steps in dashed line boxes are optional

\subsubsection{Phase-Space Thresholding method}

The Goring and Nikora (2002) PST algorithm employs a three-dimensional Poincaré map (phase-space plot) in which the fluctuating component of a time series and its first and second time derivatives are plotted against each other. Calculation of the standard deviations of the variables in each dimension and the rotation angle of the principal axis are used to construct an ellipsoid, which denotes the boundary of the Universal criterion. Any points lying outside of this ellipsoid are designated as spikes and are removed and replaced. The algorithm was originally developed to post-process ADV data; however, it is adopted for the ORNL ADCP data postprocessing code due to its robustness in identifying spikes.

Goring and Nikora do not specify an optimal method of replacement, though they mention the following as their replacement options: overall average, previous value, linear interpolation, and cubic interpolation using twelve points on either side of the removed point (their recommended method). 
The replacement method is iterated until no points lie outside of the ellipsoid, or the maximum number of iterations is reached. The ellipsoid may shrink upon iteration corresponding to the diminishing standard deviations of the velocity during subsequent iterations. No effect on further replacement is defined as a condition in which the spikes that are identified in one iteration are the same as those identified in the previous iteration; and therefore, would be identified in any subsequent iteration without change.

Parsheh et al. (2010) adapted the algorithm described by Goring and Nikora, but shared the widely held concern that the method in previous implementations identified several data points as spikes that were valid according to Parsheh et al. (2010). They also considered the effects of filtering on the power spectra and prescribed their so-called modified Phase-Space Thresholding Sample and Hold algorithm (mPST-SH).

The mPST-SH algorithm evaluates the validity of data in three stages. First, any velocity measurements near the average are incontrovertibly marked as valid. Then, any data found to depart significantly from the average are marked as invalid and are removed. It should be noted that the user provides input variables to determine this threshold of significant departure. Finally, the data are subjected to modified phase-space thresholding in which the median of the absolute deviation is used rather than the standard deviation since the former is more robust and values termed as spikes are replaced. However, if any of the data points which the PST filter identified as spikes were previously identified as incontrovertibly valid (those near the average), they are not replaced. Parsheh et al. (2010) adopted replacement by the last valid point as their replacement strategy and did not examine the effects of other replacement methods.

\subsubsection{Data replacements}

The replacement function allows the user to select from among replacement data by the overall average, by the previous valid point, or by polynomial interpolation. As emphasized earlier, replacement is not aimed to reconstruct the dataset, which would have been measured when errors in the dataset do not exist; but rather, to fill in the data gaps so that they are continuous with respect to time, which is the prerequisite for power spectra computation. It is always a good practice to compare the results from the different replacement methods.

\subsubsection{Spectral energy density}

One of the characteristics of turbulence is the apparent randomness of velocity fluctuations with respect to time. The statistical properties of turbulence, however, are not random. The instantaneous value of a velocity component $(u)$ can be decomposed into the time-averaged velocity $(U)$, which has a constant value for steady flow, and the fluctuating component $(u$ '), which has an apparent random value with respect to time (Figure 3-2). The spectral energy density (SED) is calculated by decomposing the time series of instantaneous velocity into a set of periodical sine functions with various amplitudes and frequencies, then plotting the amplitude of each periodical function versus their frequency on a log scale. The frequency of the periodical functions is inversely proportional to the time scale of the eddies and, hence, their size. Large eddies correspond to the lower frequency domain and vice versa. Nezu and Nakagawa (1993)

suggest that the minimum sampling frequency of the instrument should be greater than $\frac{50 U}{\pi H}$ to analyze the spectral distribution down to the viscous subrange. 


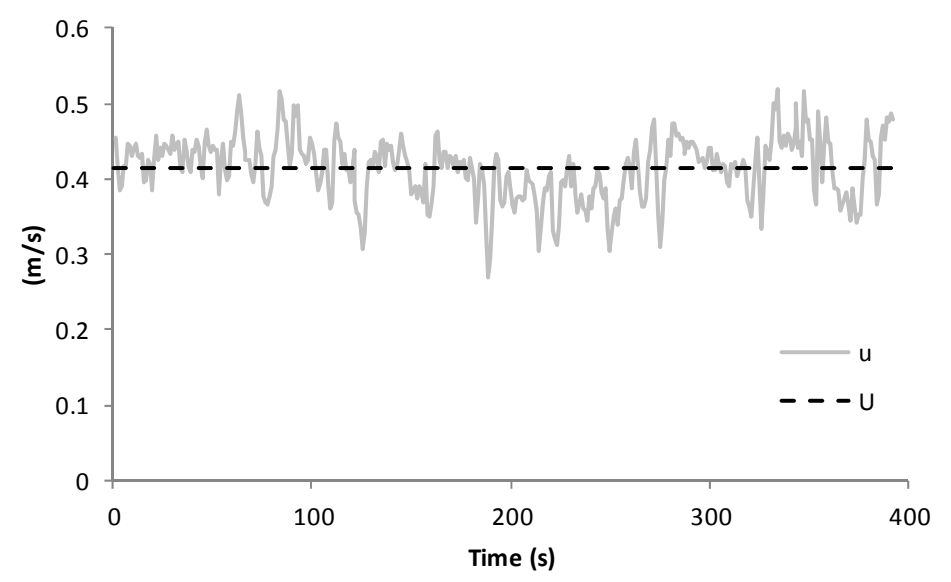

Figure 3.2 Decomposition of $u$ into $U$ and $u$ '

The SED can be computed via the autocorrelation of velocity where the autocorrelation of the streamwise velocity component is expressed as

$$
R_{u u}(\tau)=<u(t) u(t+\tau)>
$$

and $u=$ velocity component in the streamwise direction, $t=$ fixed time, $\tau=$ time shift and $<>$ denotes ensemble averaging (Landahl and Mollo-Christensen 1992). The SED of Equation (3.1) for a discrete measurement time of $T$ can be expressed as

$$
S_{u u}(T, f)=\int_{-T}^{T} R_{u u}(T, \tau) e^{-i 2 \pi f \tau} d \tau=\frac{\left|S_{u}(T, f)\right|^{2}}{T}
$$

where $S_{u}$ is the Fourier transform of $u u, f=$ frequency band, $i=$ imaginary unit number with $i^{2}=$ 1 (Pope 2000; Howard 2002). The ORNL ADCP data post-processing code computes the SED using the expression on the right hand side of Equation (3.2). The proof of the equality expressed by Equation (3.2).can be found in Howard (2002, page 81). It first computes the SED of the fluctuating component of the velocity, squares its absolute value and then divides it with the total sampling time. The spectral energy densities contained beyond $1 / 2 f_{R}$ experience aliasing, which constitutes a potential source of error (Bendat and Piersol 1971, page 28). Hence, only the spectral energy densities contained up to $1 / 2 f_{R}$ (often termed as the Nyquist or folding frequency) are plotted. Due to the relatively low sampling rate, only the lower frequency domain of the SED can typically be observed.

Spectral leakage occurs due to the existence of SED values within a frequency band not represented in the fast Fourier transform ( $f f t$ computation. The power in that frequency band leaks to the neighboring bands, often resulting in a fluctuating SED curve (see Bendat and Piersoll 1971 for more details). A window function is often used to attenuate the fluctuations. The ORNL ADCP data post-processing code uses $50 \%$ overlapping windows by default, where the user provides the number of windows (nwin) to be used as input. An nwin value of 1 will not apply this smoothing technique. The effect of changing nwin is illustrated in Figure 3.3. Rather than using ADCP data, ADV data are used in this example for better clarity. A higher value of 
nwin increases smoothing, but also the lowest frequency of the SED. An nwin value will have a different smoothing level in two datasets if the number of samples of those datasets is different. In order to have a similar level of smoothing, a dataset with a high number of samples requires a higher $n$ win value than the nwin value used for a dataset with a low number of samples. When the SED plot is used to determine the peaking of energy at a certain frequency, and its peak value, the user should recognize that the magnitude of the peaks may change with the smoothing level.

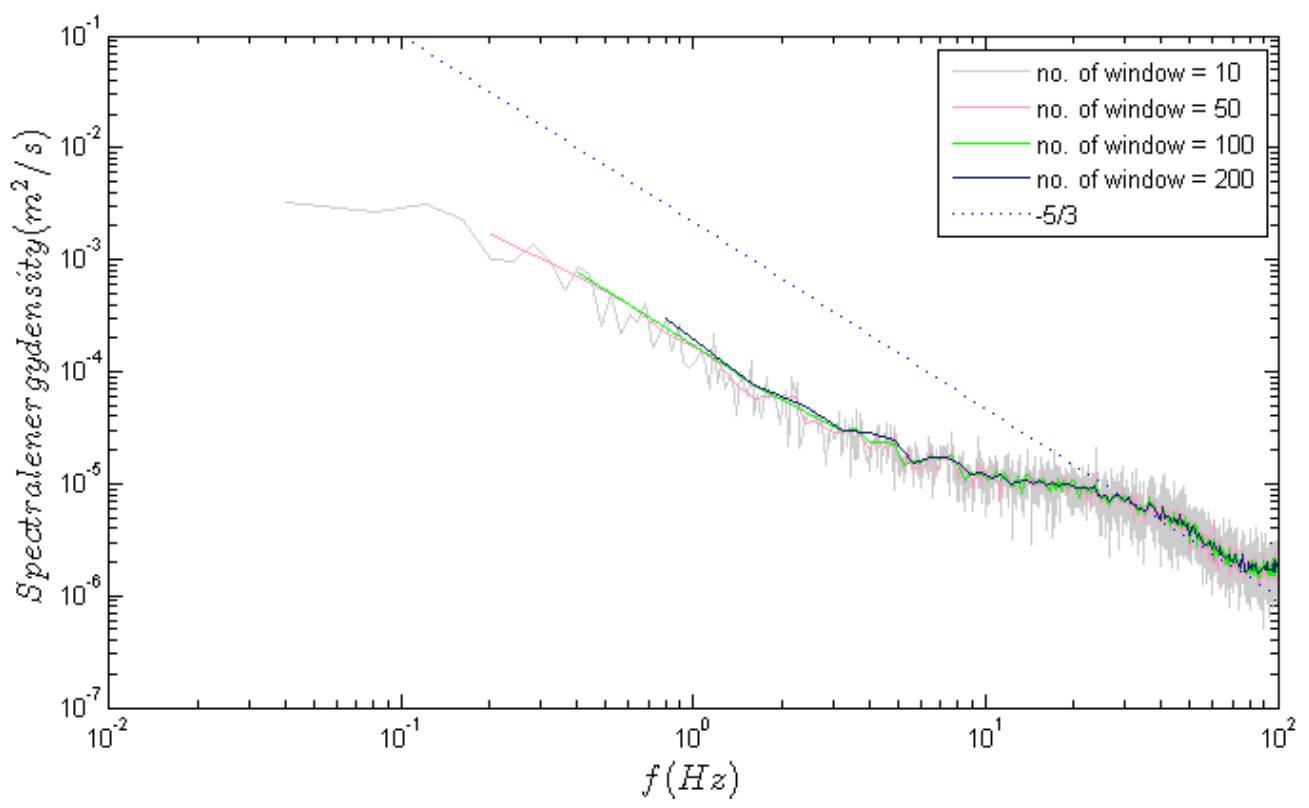

Figure 3.3 Spectral energy density plot for $u$

\subsection{INPUT/OUTPUT}

At the time this report is being written, the ORNL ADCP data post-processing code is being compiled in order to provide users with a standalone program that can be run without having the MATLAB software. The ORNL ADCP data post-processing code requires the ADCP's three components of velocity and the bin location which should be arranged as in the example shown in Figure 3.4. Block 1 is reserved for bin location with increment in the rows and columns number indicating increment in measurement time (sample number) and distance from the transducers, respectively. Blocks 2, 3 and 4 are for $u, v$ and $w$ respectively. The bin location and measurement time for each $u, v$ and $w$ data correspond to the same bin location and measurement time for each data in block 1 ; for example, the value of $u$ at $0.26 \mathrm{~m}$ distance from the transducers and at $t_{5}$ is $0.501 \mathrm{~m} / \mathrm{s}$ (Figure 3.4). The manufacturer software can usually output each parameter as an ASCII file in the format used for each block shown in Figure 3.4. One of the most convenient ways to create the input data is by opening each ASCII file (bin, $u, v$ and $w$ ) in Microsoft Excel, merge them together in one worksheet with the same format shown in Figure 3.4 , and then save the data as a comma separated value (*.csv) file. 


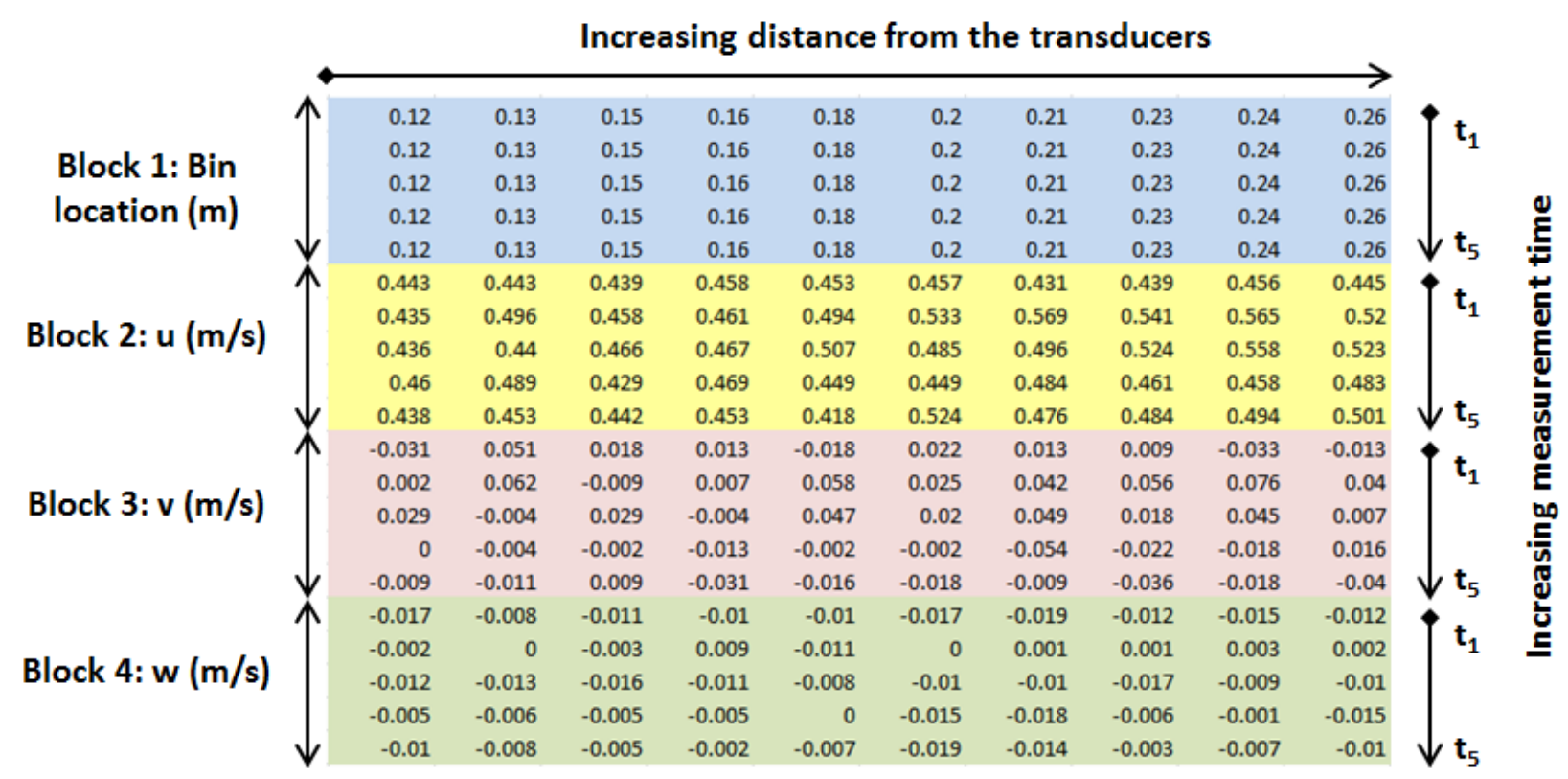

Figure 3.4 Input format for the ORNL ADCP stationary data post-processing code

The details of each output variable are listed in Table 3.1. In addition, the code can also plot the Poincaré map and velocity time series for PST and mPST methods, and the SED plots for the last bin.

Table 3.1 Output file generated by ORNL ADCP data post-processing code

\begin{tabular}{|c|c|c|}
\hline No. & Output file name & Description \\
\hline 1 & M.txt & $\begin{array}{l}\left.\text { A matrix with columns [ } U, U_{R M S}, V, V_{R M S}, W, W_{R M S}\right] \text {. RMS is one of the fluctuating } \\
\text { components, the means are the arithmetic means of velocities } u, v \text {, and } w \text { (the } X, Y \text {, } \\
\text { and } Z \text { components). }\end{array}$ \\
\hline 2 & Reynolds.txt & A matrix of the Reynolds stresses for each bin $\left[\overline{u^{\prime} u^{\prime}}, \overline{u^{\prime} v^{\prime}}, \overline{u^{\prime} w^{\prime}}, \overline{v^{\prime} v^{\prime}}, \overline{v^{\prime} w^{\prime}}, \overline{w^{\prime} w^{\prime}}\right]$ \\
\hline 3 & PST_Filter.txt & $\begin{array}{l}\text { A matrix of the number of outliers detected using the PST (or mPST) filter for each } \\
\text { bin [no. of outliers in percentage for } X \text { velocity component, no. of outliers in } \\
\text { percentage for } Y \text { velocity component, no. of outliers in percentage for } Z \text { velocity } \\
\text { component]. }\end{array}$ \\
\hline 4 & ptnos.txt & A matrix of the total number of samples in each bin [number of samples]. \\
\hline 5 & Spectra(i).txt & $\begin{array}{l}\text { A matrix that saves the velocity spectra results [frequency, } \mathrm{A} / \mathrm{X} / \mathrm{U} \text { component of } \\
\text { the velocity spectra, } B / Y / V \text { component of the velocity spectra, } \mathrm{C} / \mathrm{Z} / \mathrm{W} \text { component of } \\
\text { the velocity spectra]. The number of the output files created is the same as the } \\
\text { number of bins. }\end{array}$ \\
\hline
\end{tabular}




\subsection{DATA ANALYSIS}

The results from different filtering and replacement schemes are compared and analyzed below to provide a demonstration of the ORNL ADCP data post-processing code. The PST and mPST filtering, constant calibration parameters values $(C 1=1.1$ and $C 2=1.5)$ are tested. For each case, three data replacement methods are considered: replacement by the overall average (option 0 ), replacement by the previous valid point (option 1) and replacement by polynomial interpolation (option 2). The number of outliers detected, mean velocity, RMS velocity and power spectral densities (SED) are reported for each case. The measured data used for this analysis were obtained in the SAFL main channel flume shown in Figure 3.5.

\subsubsection{Description of the data}

Two velocity profiles were measured using a three-beam pulse-to-pulse coherent SonTek acoustic Doppler profiler (ADP) (SonTek 2001) at the centerline of the $2.75 \mathrm{~m}$ wide SAFL flume, at $1.0 \mathrm{~m}$ (case 1), $1.5 \mathrm{~m}$ (case 2) and $2.5 \mathrm{~m}$ (case 3) upstream of a 1:10 scale model of an MHK turbine with a $0.5 \mathrm{~m}$ blade diameter. The ADCP has three transducers with a slant angle of $15^{\circ}$, as shown in Figure 3.16. The ADCP bins size and sampling rate were set at $1.6 \mathrm{~mm}$ and $1 \mathrm{~Hz}$ respectively. The ADCP was fixed to a computerized traversing system (cart) capable of moving the ADCP within $1 \mathrm{~mm}$ accuracy, shown in Figure 3.5. The SonTek software ADPview was used to export the velocity data into the ASCII format. The water depth $(H)$ during the measurement was kept constant at $1.15 \mathrm{~m}$. The hub of the turbine model was located $0.425 \mathrm{~m}$ above the mean bed elevation of the flume. Another velocity profile was obtained using a Nortek Vectrino ADV (Nortek 2009), at $200 \mathrm{~Hz}$ sampling rate, at $1 \mathrm{~m}$ distance upstream of the turbine model, and is used for comparison.

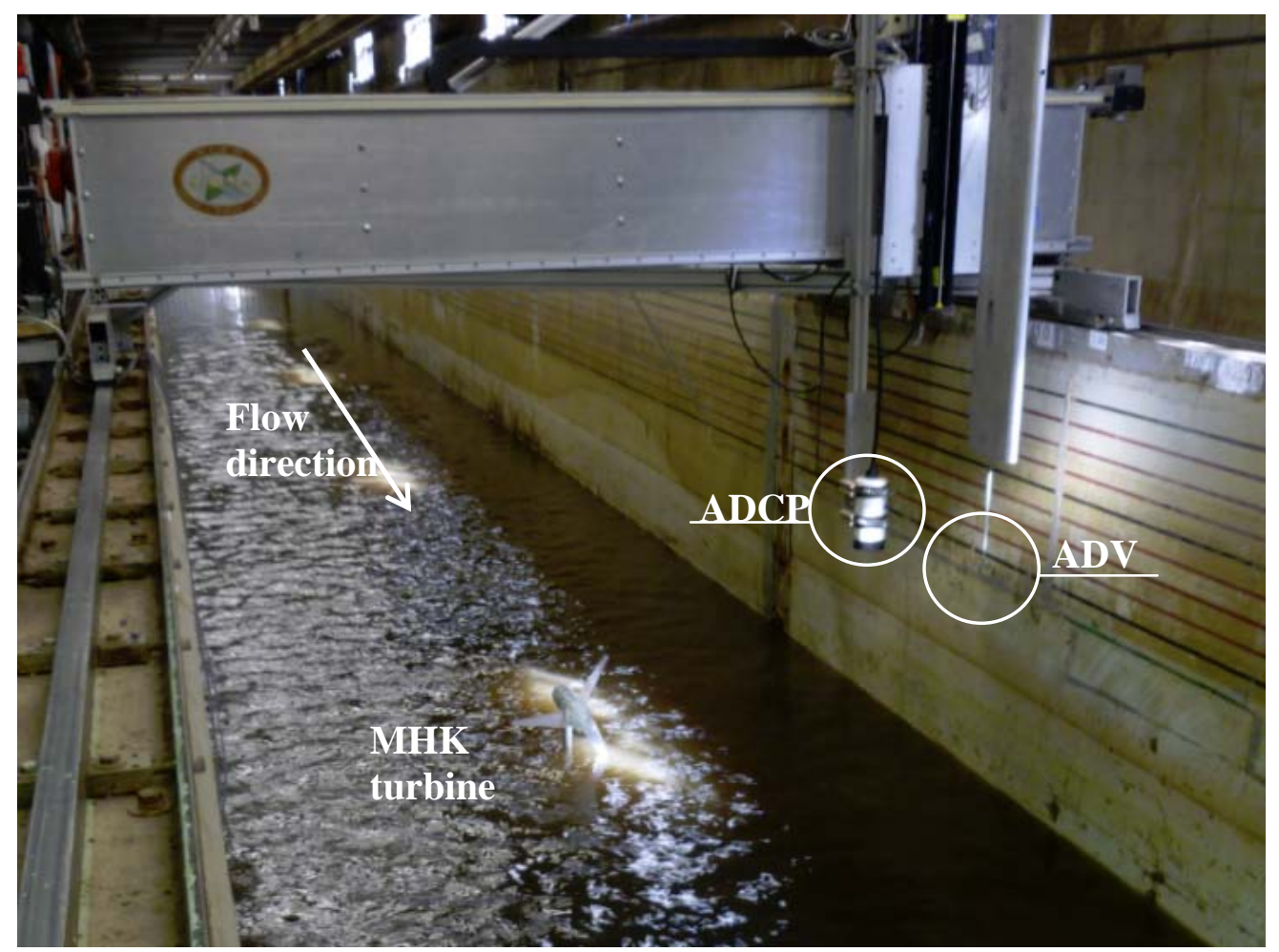

Figure 3.5 Measurement setting at the St. Anthony Falls Laboratory. 


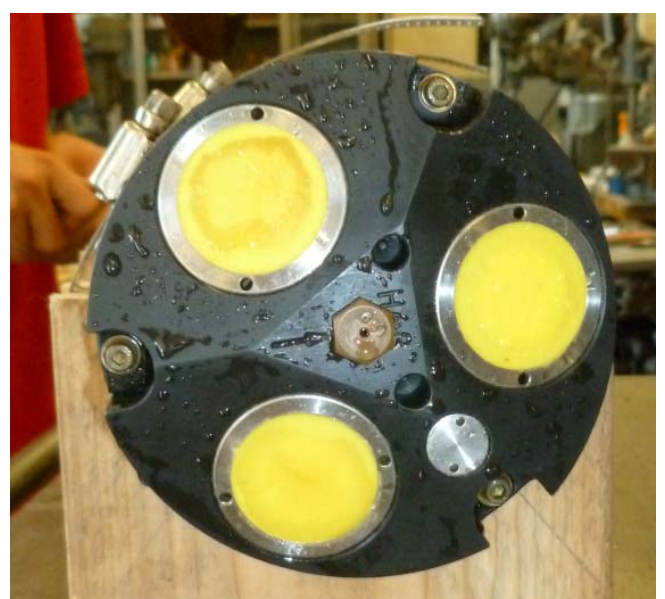

Figure 3.6 The SonTek ADP used in the experiment.

\subsubsection{Percentage of outliers}

Note that the correlation filter is not applied in the ORNL ADCP data as it tends to remove many data at the near bed region since they tend to have a correlation value lower than $50 \%$ (Figure 3.7). Low correlated data often have similar velocity and turbulence statistics to the high correlated data; and, based on this definition, can be considered as valid (see also Martin et al. 2002; Rusello 2009; Gunawan et al. 2011).

In general, the PST filters detect a higher number of outliers in the near bed region for the $X$ velocity components, for both cases (Figures 3.8, A1 and A2), which could be due to increased turbulence levels near boundary (Martin et al. 2002) and/or beam spreading. The mPST filters also detect a higher number of outliers in the near bed region, but it is much less than the PST method. Note that the number of outliers is different for each replacement scheme because the outliers are replaced for each iteration in the PST and mPST methods. For the $Y$ and $Z$ velocity components, there is no clear pattern on the effect of the distance from bed ( $z$ ) to the number of outliers (Figures 3.8, 3.9, A3-A6).

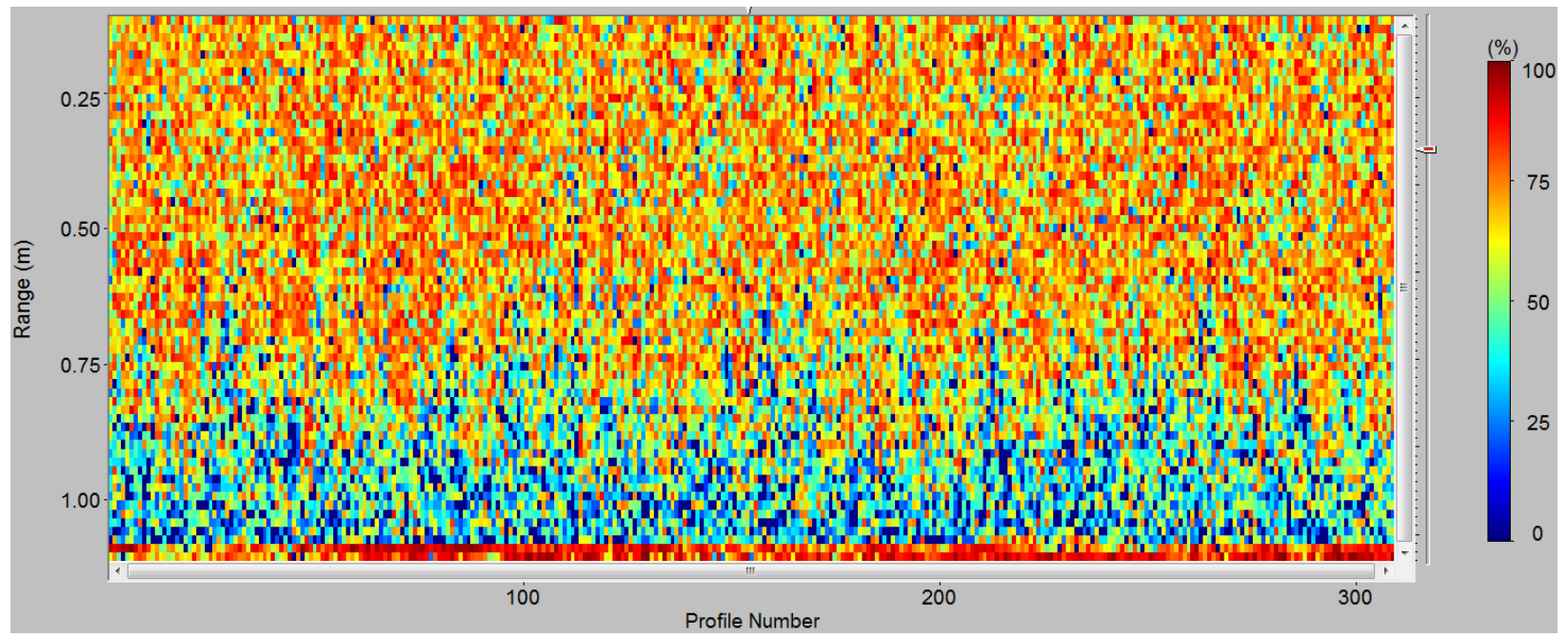

Figure 3.7 Correlation value at one of the ADCP beams for the measurement at 1.0m upstream of the turbine. 

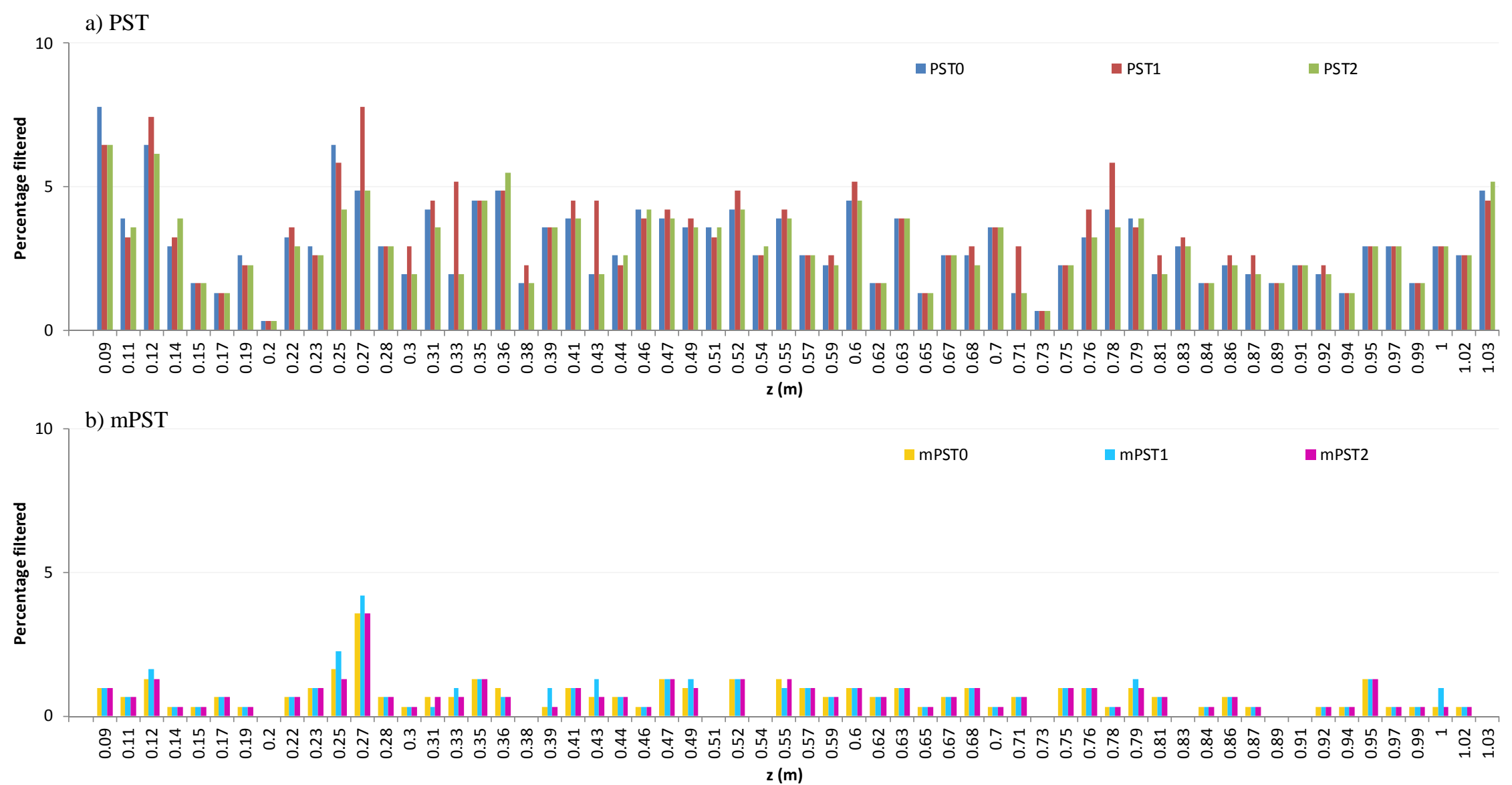

Figure 3.8 Number of outliers (in percent) at different bins for the $X$ velocity component at 1.0m upstream of the turbine model. 

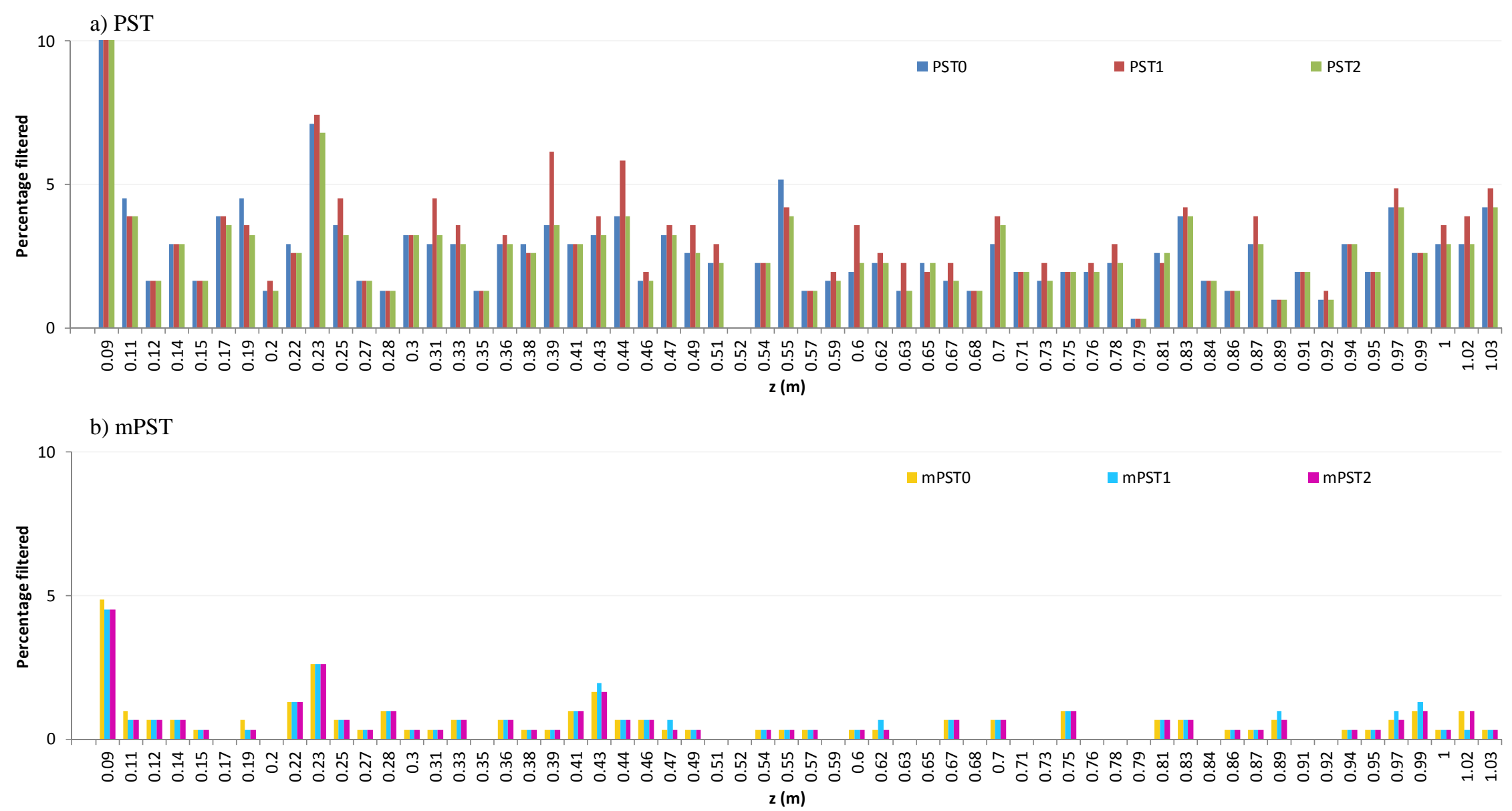

Figure 3.9 Number of outliers (in percent) at different bins for the $Y$ velocity component at 1.0m upstream of the turbine model. 

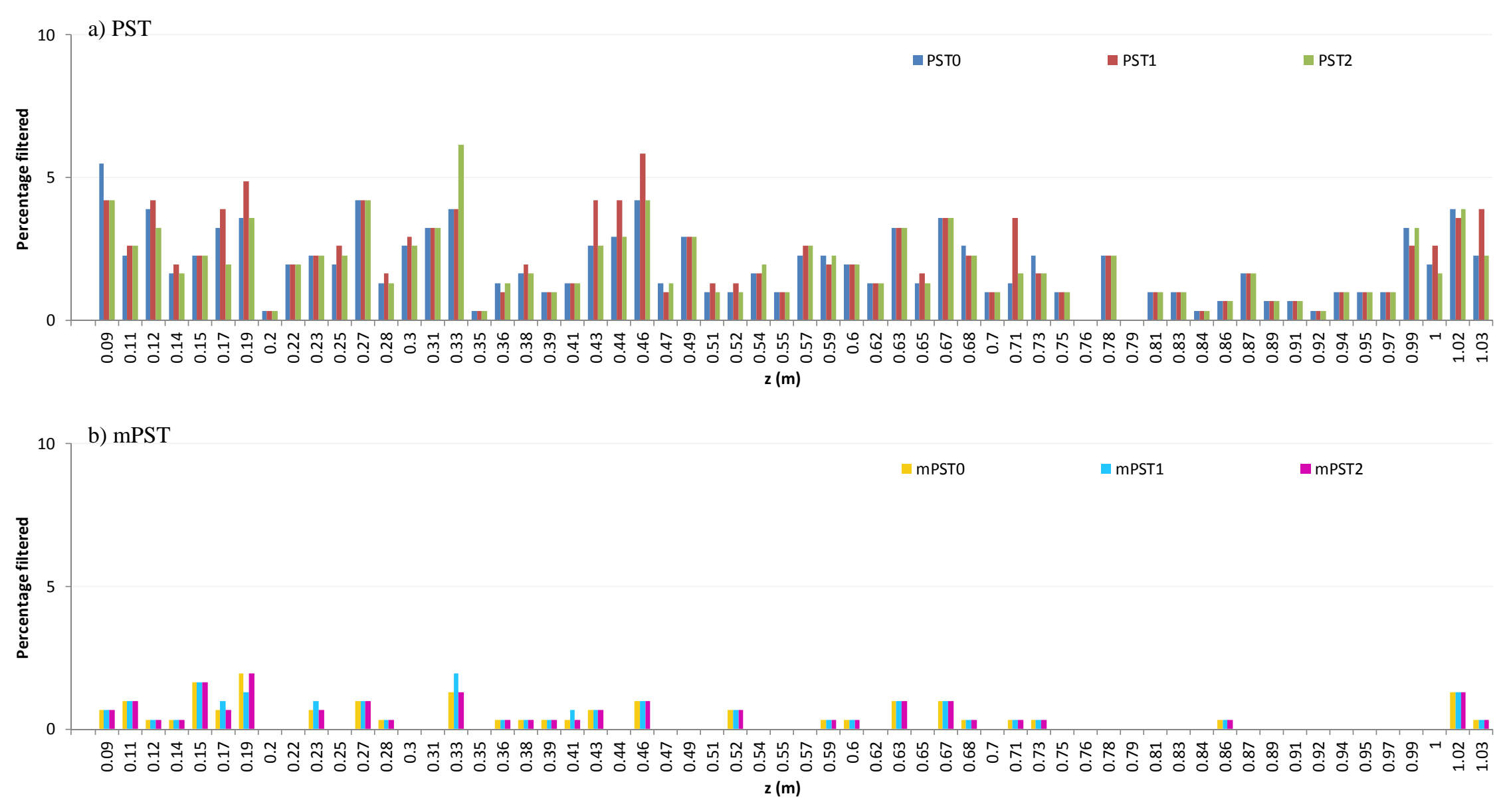

Figure 3.10 Number of outliers (in percent) at different bins for the $Z$ velocity component at 1.0m upstream of the turbine model. 


\subsubsection{Mean velocity and velocity RMS (standard deviation)}

Figure 3.11 shows the mean velocity of the $X, Y$ and $Z$ components $(U, V$ and $W$ ) for the raw ADCP data and filtered ADCP data, as well as the ADV data at $1 \mathrm{~m}$ upstream of the turbine model. The $U, V$ and $W$ of the PST and mPST filtered data do not depart significantly from the raw data, which is expected since spikes tend to be distributed at both sides of the mean velocity. Similar behavior is also observed in the cases 2 and 3 . The difference of the streamwise velocity magnitude between the ADCP and the ADV data tends to increase towards the bed. This condition appears to be caused by the beam spreading of the ADCP. The measurements are conducted at a close proximity to the turbine, a region where the velocity is expected to be highly three-dimensional. More ADCP and ADV measurements in the future at different locations at the SAFL main channel facility will provide a better assessment on the accuracy of the ADCP velocity measurement. Notwithstanding this, it is perhaps noteworthy that others have found a good agreement between the ADCP and ADV velocity data in unperturbed flows, typically within 5\% (e.g., Nystrom et al. 2007; Gunawan 2010).
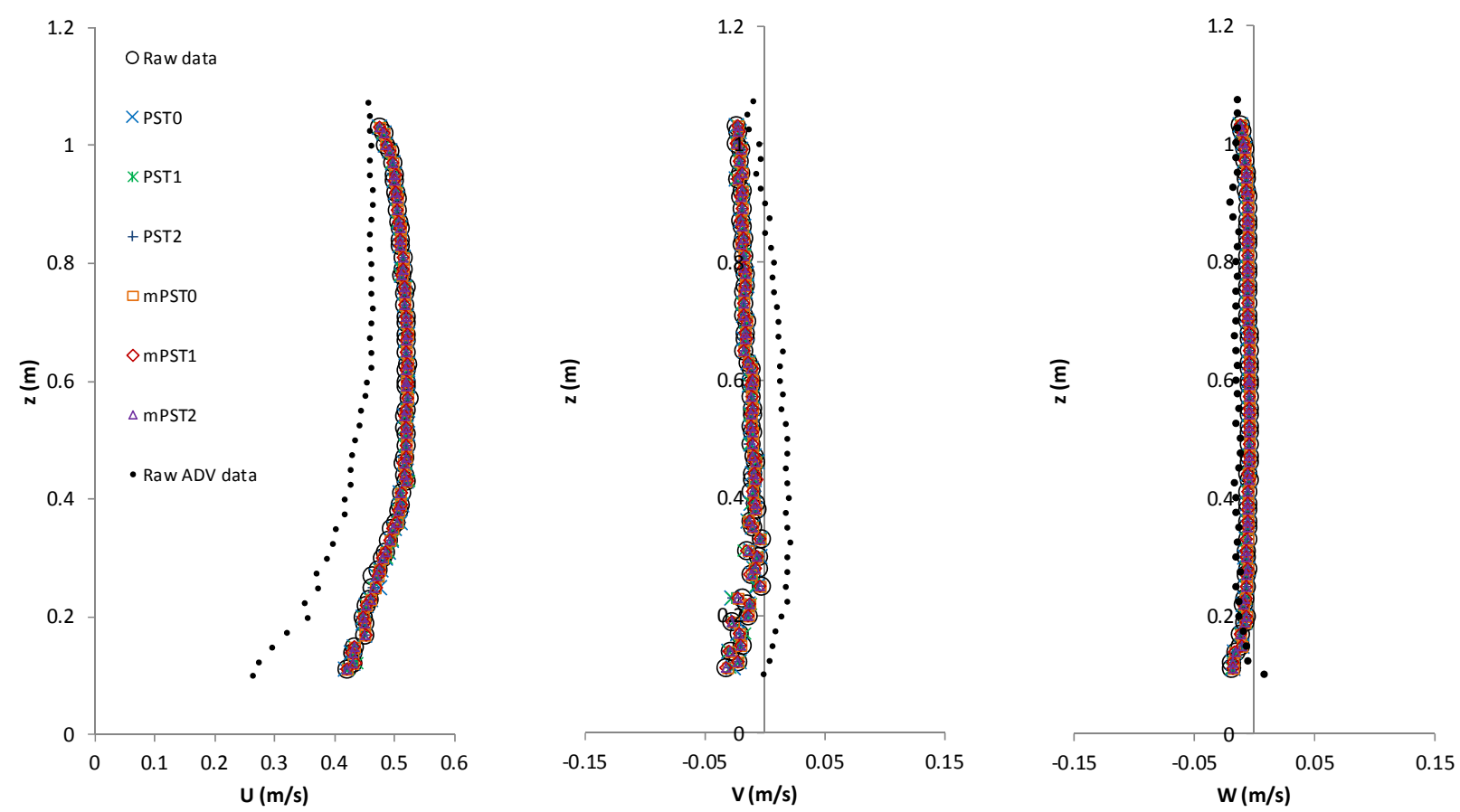

Figure 3.11 Streamwise, lateral and vertical velocities with respect to distance from bed at $1.0 \mathrm{~m}$ upstream of the turbine model.

The ADV is considered as a better instrument than the ADCP for measuring turbulence parameters due to its higher sampling frequency and smaller sampling volume. As the consequence of this, the RMS velocity magnitude measured using an ADV is generally lower than that measured using an ADCP. An example on this condition is shown in Figure 3.12. The same figure also shows that applying PST and MPST filters reduces the RMS of horizontal velocities ( $\left.U_{R M S}, V_{R M S}\right)$ and brings the values closer to the RMS velocities measured using the ADV. The reductions are observed on all cases (Figures 3.12 - 3.14), with up to $14.4 \%$ average reduction observed for the $u^{\prime}$ (Table 3.2). The largest reductions are achieved using the PST methods with replacement by the overall average and polynomial interpolation. 
The region near the bed for cases 1 and 2 experiences the largest $u$ ' reductions, perhaps due to the greater impact of the turbine (hub height $=0.425 \mathrm{~m}$, blade diameter $=0.5 \mathrm{~m}$ ) at those locations. Further from the turbine (case 2), the largest $u$ ' reductions are located at above $z=$ $0.4 \mathrm{~m}$. More measurements will be taken to attempt to provide a clarification on this issue.
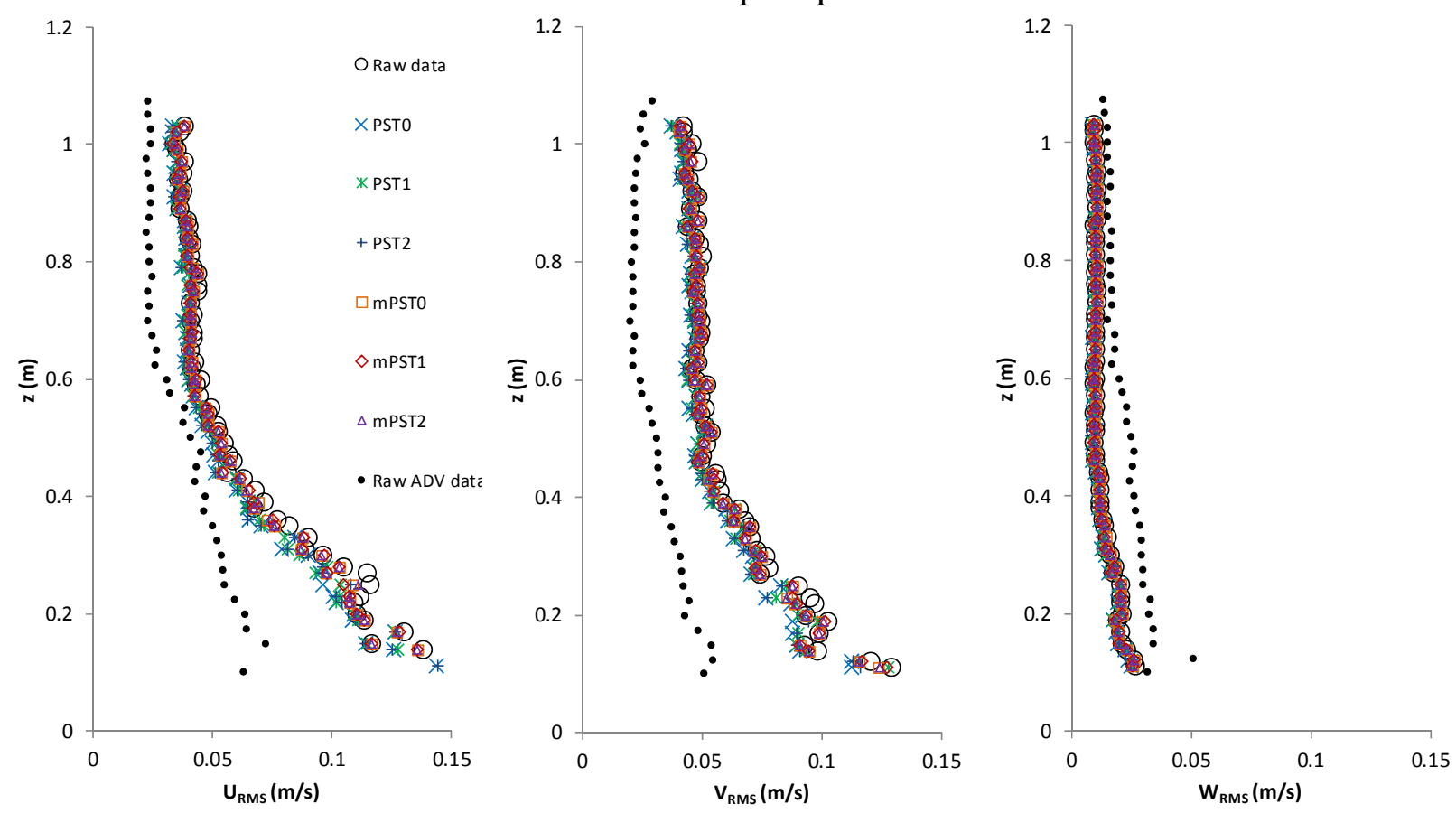

Figure 3.12 RMS values of streamwise, lateral and vertical velocities with respect to distance from bed at $1.0 \mathrm{~m}$ upstream of the turbine model.
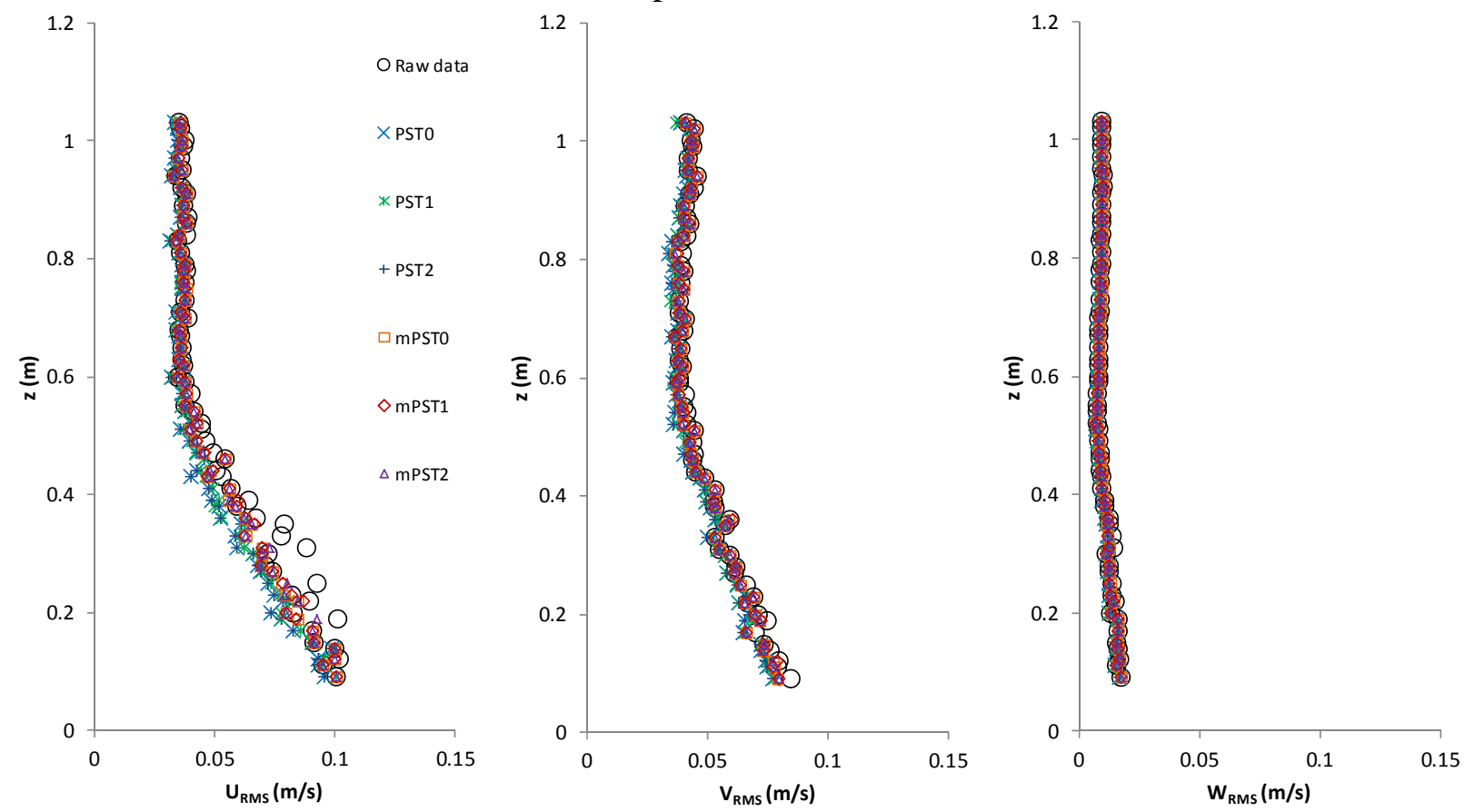

Figure 3.13 RMS values of streamwise, lateral and vertical velocities with respect to distance from bed at $1.5 \mathrm{~m}$ upstream of the turbine model. 

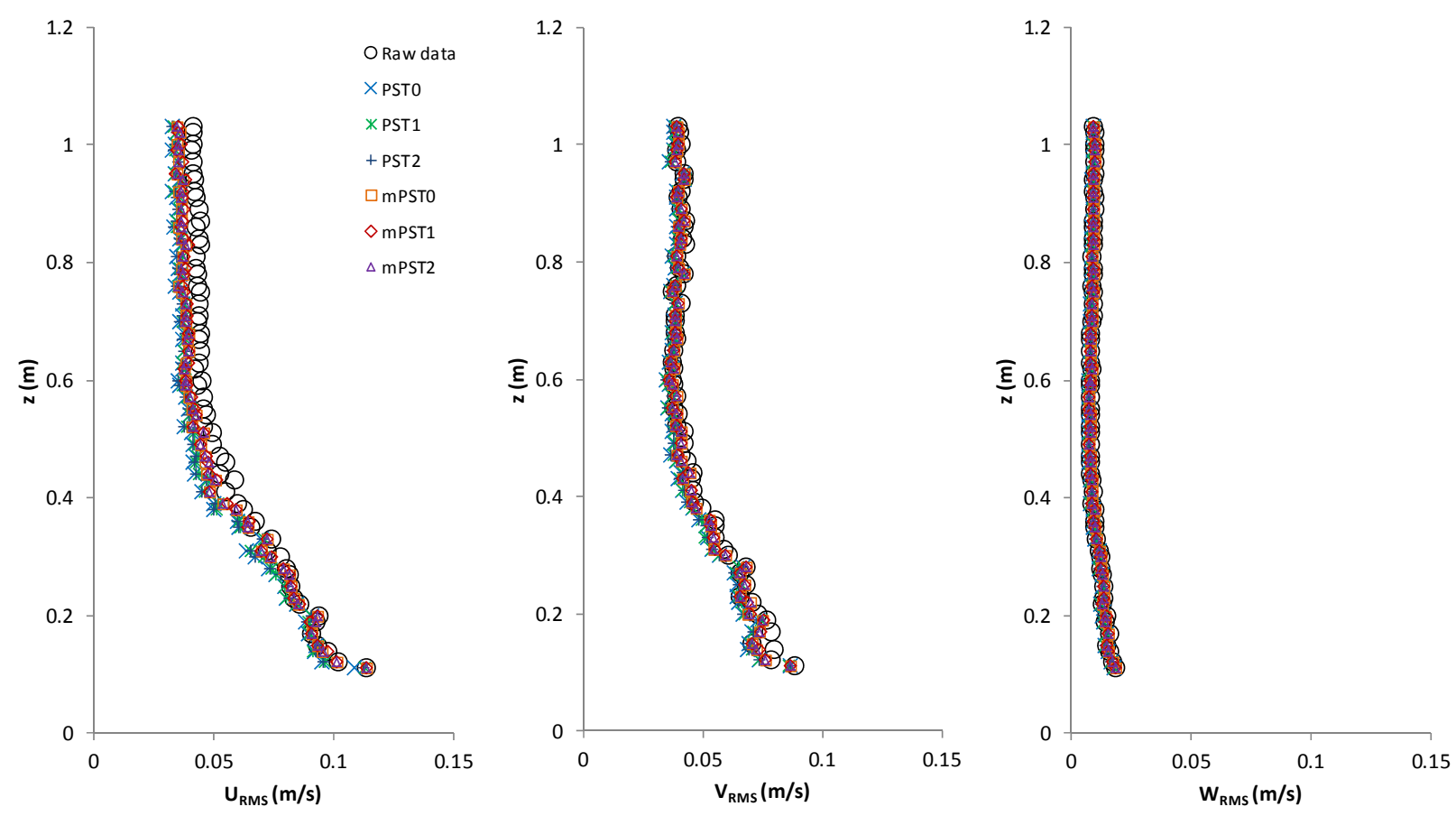

Figure 3.14 RMS values of streamwise, lateral and vertical velocities with respect to distance from bed at $2.5 \mathrm{~m}$ upstream of the turbine model.

Table 3.2 Reduction of $u$ ' after applying PST and mPST filtering (in percentage from the raw data) at $1.0 \mathrm{~m}, 1.5 \mathrm{~m}$ and $2.5 \mathrm{~m}$ upstream of the turbine model.

\begin{tabular}{lrrr} 
& $1.0 \mathrm{~m}$ & \multicolumn{1}{c}{$1.5 \mathrm{~m}$} & \multicolumn{1}{c}{$2.5 \mathrm{~m}$} \\
\hline PST0 & 7.5 & 9.0 & 14.4 \\
PST1 & 5.9 & 7.3 & 12.7 \\
PST2 & 6.9 & 9.0 & 13.9 \\
\hline mPST0 & 2.7 & 3.9 & 9.8 \\
mPST1 & 2.5 & 3.4 & 8.5 \\
mPST2 & 2.5 & 3.6 & 9.4
\end{tabular}

\subsubsection{Spectral energy density}

Only the low frequency energy densities are shown in the SED plot, as the sampling rate of the ADCP is low. Figure 3.17 shows the SED plot of the streamwise velocity component at $1.0 \mathrm{~m}$ upstream of the turbine model, at the turbine hub height $(z=0.425 \mathrm{~m})$. No part of the ADCP SED plot follows the Kolmogorov $-5 / 3$ spectrum, which applies to the inertial range (Pope 2000). This is an indication that either only the production range spectrum is obtained or the instrument noise is high, which renders the accuracy of the Spectral Energy Densities plot. 


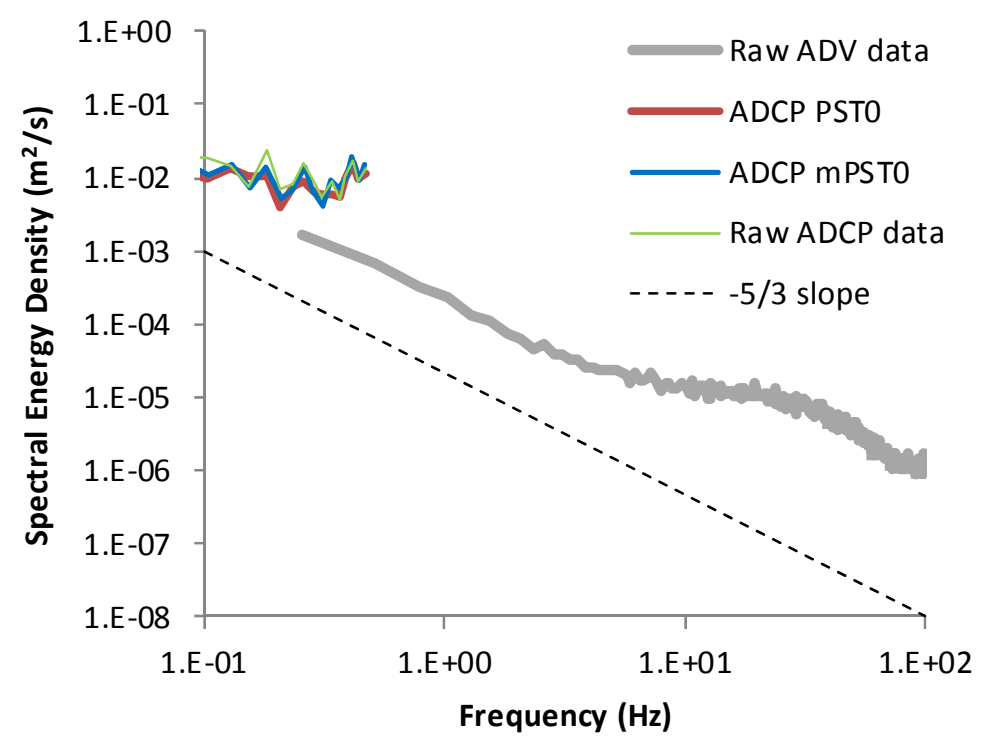

Figure 3.15 SED plot for the streamwise velocity at $1.0 \mathrm{~m}$ upstream of the turbine model (at the turbine hub height, $z=0.425 \mathrm{~m}$ ).

\subsubsection{Summary of Results}

The stationary ADCP data processed using ORNL ADCP data post-processing code and the subsequent analysis outlined in Sections 3.3.1 - 3.3.4 lead to the following conclusions:

- There is not a significant change in the mean velocities from the raw data, when the data are processed using correlation filter, PST and mPST methods. This is because the outliers are equally distributed on both sides of the mean in the velocity histogram. When the outliers are not distributed equally on both sides, the change of the mean velocities from the raw data will likely be more significant.

- PST and mPST provide an improvement on the data contaminated with spikes by removing the spikes from the velocity time series and replacing the outliers. Both methods reduce the RMS/standard deviation of the velocity data associated with the spikes and bring them closer to the ADV measurement. Hence, the methods should be used before calculating turbulence intensities and Reynolds stresses of data contaminated with spikes.

- The spectral energy densities plot, based on the ADCP data, is not suitable to analyze the turbulent scales down to the viscous range due to the low sampling frequency, large sampling volume and beam spreading of the ADCP.

- The PST does not require parameterization, which is considered a practical advantage over the mPST method. 


\section{FUTURE WORK}

The ORNL ADCP data post-processing code provides an integrated tool to detect and replace outliers using different methods, as well as to calculate important parameters for designing and monitoring MHK devices, as well as estimating the available power density and annual energy production at an MHK site. In order to improve and broaden the capability of the code, some additional functions listed below will be added in the future:

1. Spatial averaging of velocity data obtained using ship-mounted ADCPs.

2. Calculation of the shear velocity from the data obtained from the ADCP stationary measurement.

3. The addition of a plotting tool for mean velocity and velocity RMS. 


\section{REFERENCES}

Baldwin, J. T., Deutsch, S., Petrie, H. L. and Tarbell, J. M. (1993). Determination of principal Reynolds stresses in pulsatile flows after elliptical filtering of discrete velocity measurements. J. Biomech. Eng., v 115, I4a, pg 396-404.

Barua, D.K. and Rahman, K.H. (1998). Some aspects of turbulent flow structure in large alluvial rivers. Journal of Hydraulic Research, IAHR, 36,235-252.

Bendat, J. and Piersol, A. (1971). Random data: Analysis and measurement procedures. John Wiley and Sons, Inc.

Carr, M.L and Rehman, C.R. (2007). Measuring the dispersion coefficient with Acoustic Doppler Current Profilers. Journal of Hydraulic Engineering, ASCE, Vol. 133, No. 8.

Cheng, R. T., C. H. Ling and J. W. Gartner. (2000). Direct measurement of turbulence properties by a BB-ADCP in bottom boundary layer, Interactions between Estuaries,Coastal Seas and Shelf Seas, Ed. T. Yanagi, pp. 37-55.

Dinehart, R.L. \& Burau, J.R. (2005a). Averaged indicators of secondary flow in repeated acoustic Doppler current profiler crossings of bends. Water Resources Research, Vol. 41.

Dinehart, R.L. \& Burau, J.R. (2005b). Repeated surveys by acoustic Doppler current profiler for flow and sediment dynamics in a tidal river. Journal of Hydrology, XX 1-21.

Einstein, H. A. and Li, H. (1958). Secondary currents in straight channels. Transactions of the American Geophysical Union, Vol. 39, No.6, pp 1085-1088.

Epler, J., Polagye, B., and Thomson, J. (2010). Shipboard acoustic Doppler current profiler surveys to assess tidal current resources, MTS/IEEE Oceans 2010, Seattle, WA, September 20-23.

Fontaine, A.A., Ellis, J.T., Healy, T.M., Hopmeyer, J. and Yoganathan, A.P. (1996). Identification of peak stresses in cardiac prostheses: A comparison of two-dimensional versus three-dimensional principal stress analyses. American Society Artificial Internal Organs Journal, Vol. 42, pp. 154-163.

Goring, D. G. and Nikora, V. I. (2002). Despiking acoustic Doppler velocimeter data. J. Hydraulic Eng., 128(1) 117-126.

Gunawan, B., Sun, X., Sterling, M., Knight, D. W., Shiono, K., Chandler, J., Rameshwaran, P., Wright, N. G., Sellin, R. H. J., Tang, X. and Fujita, I. (2008). An integrated and novel approach to estimating the conveyance capacity of the River Blackwater. Proceedings of the Eight International Conference on Hydro-Science and Engineering, Nagoya, Japan, 
September 8-12.

Gunawan, B. (2010). A study of flow structures in a two-stage channel using field data, physical model and numerical modelling, PhD thesis, University of Birmingham, UK.

Gunawan, B., Sterling, M. and Knight, D. W. (2010a). Using an acoustic Doppler current profiler in a small river. Water and Environment Journal, 24: 147-158. doi: 10.1111/j.17476593.2009.00170.x

Gunawan, B., Sterling, M., Tang, X. and Knight, D. W. (2010b). Measuring and modeling flow structures in a small river. Proceeding of the International Conference on Fluvial Hydraulics, Braunschweig, Germany, September 8-10.

Gunawan, B., Neary, V. S. and McNutt, J. R. (2011). ORNL ADV post-processing guide and MATLAB algorithms for MHK site flow and turbulence analysis. ORNL/TML-2011.

Howard, R. M. (2002). Principles of random signal analysis and low noise design: The power spectral density and its applications. Wiley-IEEE Press; 1st edition (August 8).

Holmes, R.R. and Garcia, M.H. (2002). Velocity and sediment concentration measurements over bedforms in sand-bed rivers. Proceedings of the ASCE/IAHR Hydraulic Measurements \& Experimental Methods Conference, Estes Park, CO (CD-ROM).

Holmes, R. R. and Garcia, M. H. (2008). Flow over bedforms in a large sand-bed river: A field investigation. Journal of Hydraulic Research, 46(3): p. 322-333.

Ikeda, S., Sano, T., Fukumoto, M. And Kawamura, K. (2001) Organised horizontal vortices and lateral sediment transport in compound channel flows, Journal of JSCE.

Klein, H. (2003). Investigating sediment re-mobilisation due to wave action by means of ADCP echo intensity data field data from the Tromper Wiek, western Baltic Sea estuarine. Coastal and Shelf Science 58 (2003) 467-474

Knight, D.W., Aya, S., Ikeda, S., Nezu, I and Shiono, K. (2009). Flow structure (Chapter 2) in Flow and sediment transport in compound channels, e.d. Ikeda, S. and McEwan, I.K. IAHR Monograph. IAHR Spain.

Landahl, M. T. and Mollo-Christensen, E. (1992). Turbulence and random processes in fluid mechanics. Cambridge University Press.

Le Coz, J., Gilles, P., Magali, J., and Andre, P. (2007). Mean vertical velocity profiles from ADCP river discharge measurement datasets, Proceedings 32nd Congress of International Association of Hydraulic Engineering and Research (CD-ROM).

Lemmin, U. and Rolland, T. (1997). Acoustic velocity profiler for laboratory and field studies. Journal of Hydraulic Engineering, ASCE, Vol.123/12. 
Lohrmann, A., Hackett, B. and Røed, L. P. (1990). High resolution measurements of turbulence, velocity and stress using a pulse-to-pulse coherent sonar. J. Atmos. Oceanic Technol., 7, 1937. doi: 10.1175/1520-0426(1990)007<0019:HRMOTV>2.0.CO;2

Luznik, L., Gurka, R., Nimmo Smith, W. A. M., Zhu, W., Katz, J. and Osborn, T. R. (2007). Distribution of energy spectra, Reynolds stresses, turbulence production, and dissipation in a tidally driven bottom boundary layer, Journal of Physical Oceanography, vol. 37, pp.15271550.

Martin, V., Fisher, T. S. R., Millar, R. G. and Quick, M. C. (2002). ADV data analysis for turbulent flows: Low correlation problem. Proceedings of Hydraulic Measurements and Experimental Methods Conference 2002. ASCE Conf. Proc. doi:10.1061/40655(2002)101

Merckelbach, L.M. (2006). A model for high-frequency acoustic Doppler current profiler backscatter from suspended sediment in strong currents. Continental Shelf Research, 26/1316-1335.

Mueller, D.S. (2003). Field Evaluation of boat-mounted Acoustic Doppler instruments used to measure streamflow. Proc. of the IEEE/OES Seventh Working Conference on Current Measurement Technology.

Mueller, D.S., and Wagner, C.R. (2009). Measuring discharge with acoustic Doppler current profilers from a moving boat: U.S. Geological Survey Techniques and Methods 3A-22, 72 p. U.S. Geological Survey. Online material available at http://pubs.water.usgs.gov/tm3a22. (last accessed 9/19/2011).

Muste, M., Yu, K. and Spasojevic, M. (2004a). Practical aspects of ADCP data use for quantification of mean river flow characteristics; Part I: Moving-vessel measurements. Flow Measurement and Instrumentation, 15(1), 1-16.

Muste, M., Yu, K., Pratt, T. and Abraham, D. (2004b). Practical aspects of ADCP data use for quantification of mean river flow characteristics; Part II: Fixed-vessel measurements. Flow Measurement and Instrumentation, 15(1), 17-28.

Neary, V. S. and Sale, D. C. (2010). Flow characteristics of river resources for hydrokinetic energy conversion. Conference Proceedings, HydroVision International, July 27-30, 2010, Charlotte, NC.

Neary, V. S., Chamorro, L., Hill, C., Gunawan, B., Sotiropolous, F. and Kang, S. K. (2011a). Experimental study of the effects of turbulence and large coherent structures on hydrokinetic turbines. Poster presentation. HydroVision International, July 19-22, 2011, Sacramento, CA.

Neary, V. S., Gunawan, B., Bevelhimer, M. S., Polagye, B., Thomson, J., Richmond, M.C., Durgesh, V., Muste, M. and, Fontaine, A. (2011b). Field measurements for MHK site development: Best practices manual. ORNL/TML-2011. 
Nezu, I. and Nakagawa, H. (1993). Turbulence in open-channel flows. IAHR Monograph Series, A. A. Balkema, Rotterdam

Nortek. (2009). Vectrino velocimeter user guide. Online material available at http://www.nortekusa.com/en/support/manuals (last accessed 9/19/2011)

Nystrom, E. A., Rehmann, C. R., and Oberg, K. A. (2007). Evaluation of mean velocity and turbulence measurements with ADCPs. Journal of Hydraulic Engineering, ASCE, Vol.133/12.

Oberg, K.A. (2002). In search of easy-to-use methods for calibrating ADCP's for velocity and discharge measurements. Proc. Hydraulic Measurements \& Experimental Methods 2002 CDROM.

Oberg, K. \& Mueller, D.S. (2007). Validation of Streamflow Measurements Made with Acoustic Doppler Current Profilers. Journal of Hydraulic Engineering, ASCE, Vol.133/12.

Parsheh, M., Sotiropoulos, F. and Port'e-Agel, F. (2010). Estimation of Power Spectra of acoustic-Doppler velocimetry data contaminated with intermittent spikes. J. Hydraulic Eng. ASCE, Vol.136, 368 (2010); doi:10.1061/(ASCE)HY.1943-7900.0000202.

Petrie, H. L., Samimy, M. and Addy, A. L. (1988). Laser Doppler velocity bias in separated turbulent flows. Exp. in Fluids, v 6, pg 80-88.

Perkins, H. J. (1970). The formation of streamwise vorticity in turbulent flow. Journal of Fluid Mechanics, Cambridge University Press, 44 (04): 721-740.

RD Instruments. (1996). Acoustic Doppler current profilers - principle of operation, A practical primer. San Diego, CA, RD Instruments.

RD Instruments. (1998). ADCP Coordinate transformation: Formulas and calculations. Teledyne RD Instruments, Inc., San Diego, California.

RD Instruments. (2011a). ADCP brochures Online material available at http://www.rdinstruments.com/default.aspx (last accessed 9/19/2011).

RD Instruments. (2011b). Introduction to the method used for measuring velocity profiles with BroadBand ADCP. Online material available at http://www.rdinstruments.com/tips/tips.aspx\#primer (last accessed 9/19/2011).

Rennie, C.D., Millar, R.G. \& Church, M.A. (2002). Measurement of bed load velocity using an Acoustic Doppler Current Profiler. Journal of Hydraulic Engineering, ASCE, Vol.128/5.

Rennie, C.D. \& Church, M. (2007). ADCP shear stress and bedload transport in a large wandering gravel-bed river. IAHR Venice Congress 2007. 
Rowe, F. and J. Young (1979). An ocean current profiler using Doppler sonar, Oceans '79 Proceedings.

Rusello, P. J. (2009). A practical primer for pulse coherent instruments, Nortek technical note No.: TN-027.

Sellin R.H.J. (1964). A laboratory investigation into the interaction between the flow in the channel of a river and that over its floodplain, La Houille Blanche, Vol. 19, No. 7, pp 793801.

Shih, H.H., Payton, C., Sprenke, J. \& Mero, T. (2000). Towing basin speed calibration of acoustic Doppler current profiling instruments. Proc. 2000 Joint Conf. on Water Resources Engineering and Water Resources Planning and Management, ASCE, Reston, Va.

Sime, L.C., Ferguson, R.I. \& Church, M. (2007). Estimating shear stress from moving boat acoustic Doppler velocity measurements in a large gravel bed river. Water Resources Research, Vol. 43.

Simpson, M.R. (2001). Discharge Measurements Using a Broad-Band Acoustic Doppler Current Profiler. Online material available at http://pubs.usgs.gov/of/2001/ofr0101/text.pdf (last accessed: 9/19/2011).

Stone, M.C. and Hotchkiss, R.H. (2007). Evaluating velocity measurement techniques in shallow streams. Journal of Hydraulic Research, IAHR, Vol. 45, No. 6, pp. $752-762$.

SonTek. (2001). Acoustic Doppler profiler technical documentation.

Stacey, M. T., Monismith, S. G., and Burau, J. R. (1999). Measurements of Reynolds stress profiles in unstratified tidal flow. Journal of Geophysical Research-Oceans, 104(C5), 1093310949.

Szupiany, R.N., Amsler, M.L., Best, J.L. \& Parsons, D.R. (2007). Comparison of fixed- and moving-vessel flow measurements with an aDP in a large river. Journal of Hydraulic Engineering, ASCE, pp. 1299-1309

Thomson J., Polagye, B., Richmond, M., and Durgesh, V. (2010). Quantifying turbulence for tidal power applications, MTS/IEEE Oceans 2010, Seattle, WA September 20-23.

Turnipseed, D.P. (2002). Tidal Flux Variation in the Lower Pearl River and Lake Pontchartrain Estuaries of Mississippi and Louisiana. Proceedings of the Hydraulic Measurements and Experimental Methods Conference 2002.

Wahl, T. L. (2003). Discussion of despiking acoustic Doppler velocimeter data. J. Hydraulic Eng., 129(6), 484 - 487. 
APPENDIX: NUMBER OF OUTLIERS FOR CASES 2 AND 3

Page | 42 

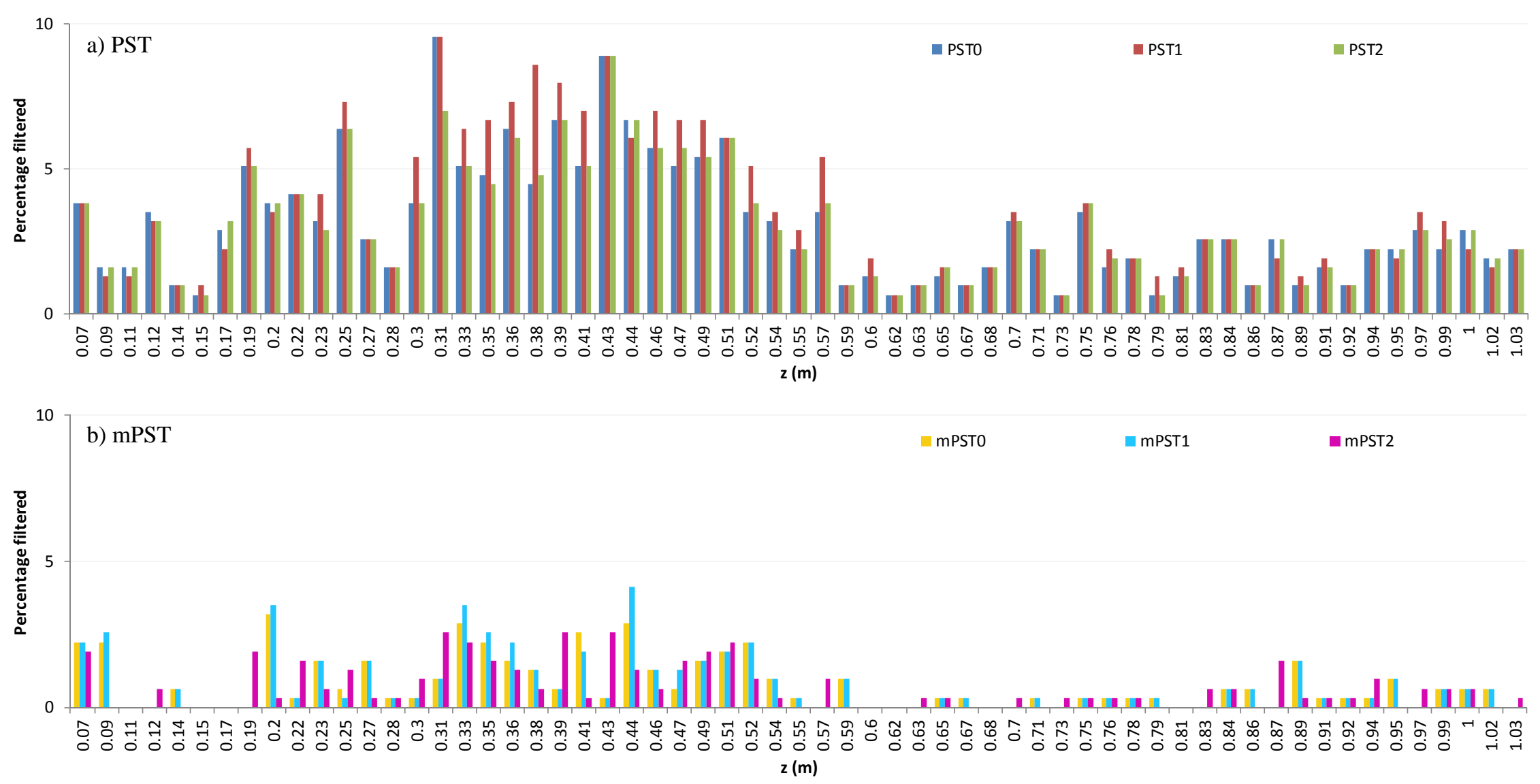

Figure A1 Number of outliers (in percent) at different bins for the $X$ velocity component at 1.5m upstream the turbine model. 

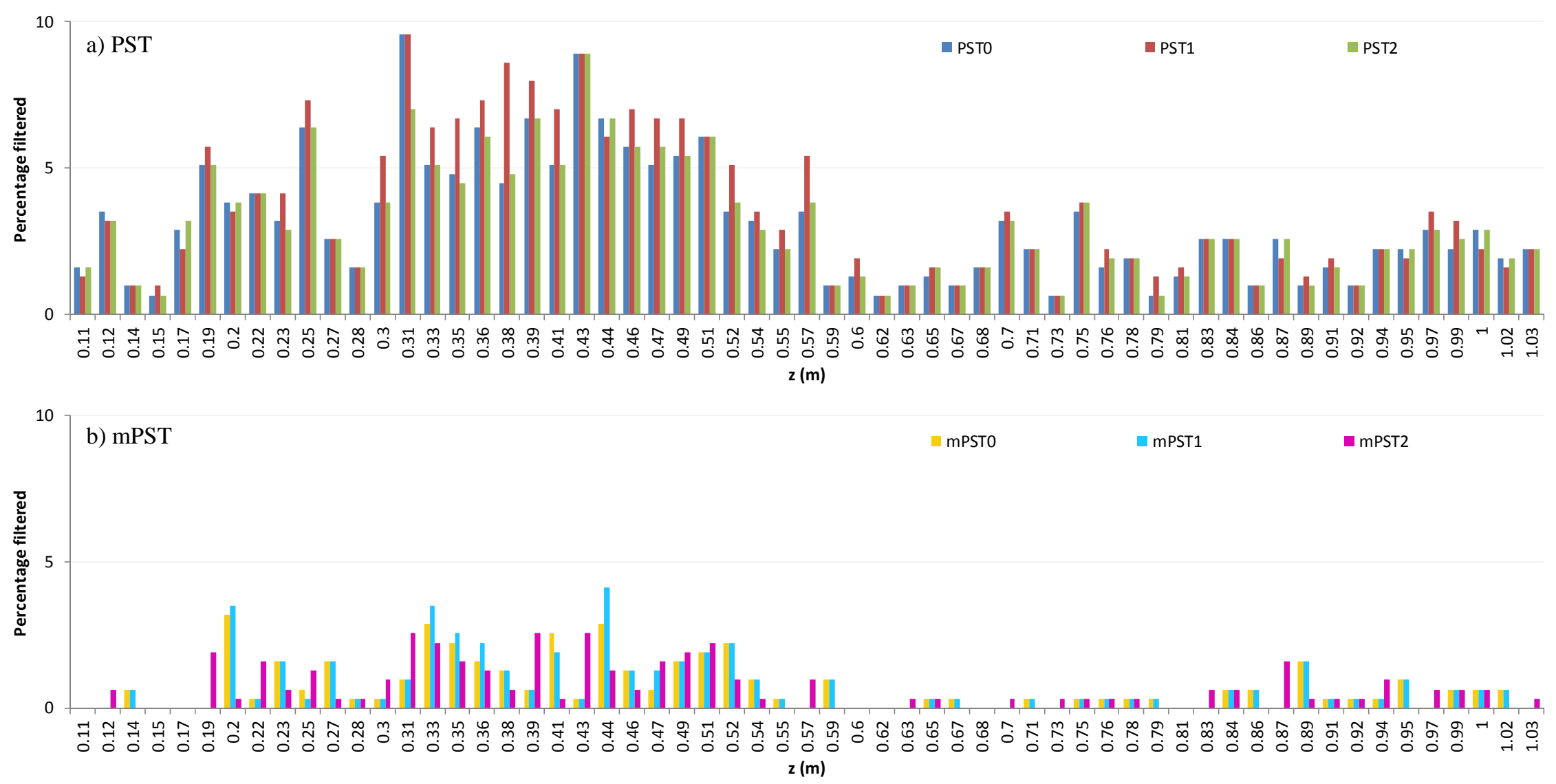

Figure A2 Number of outliers (in percent) at different bins for the $X$ velocity component at 2.5m upstream the turbine model. 

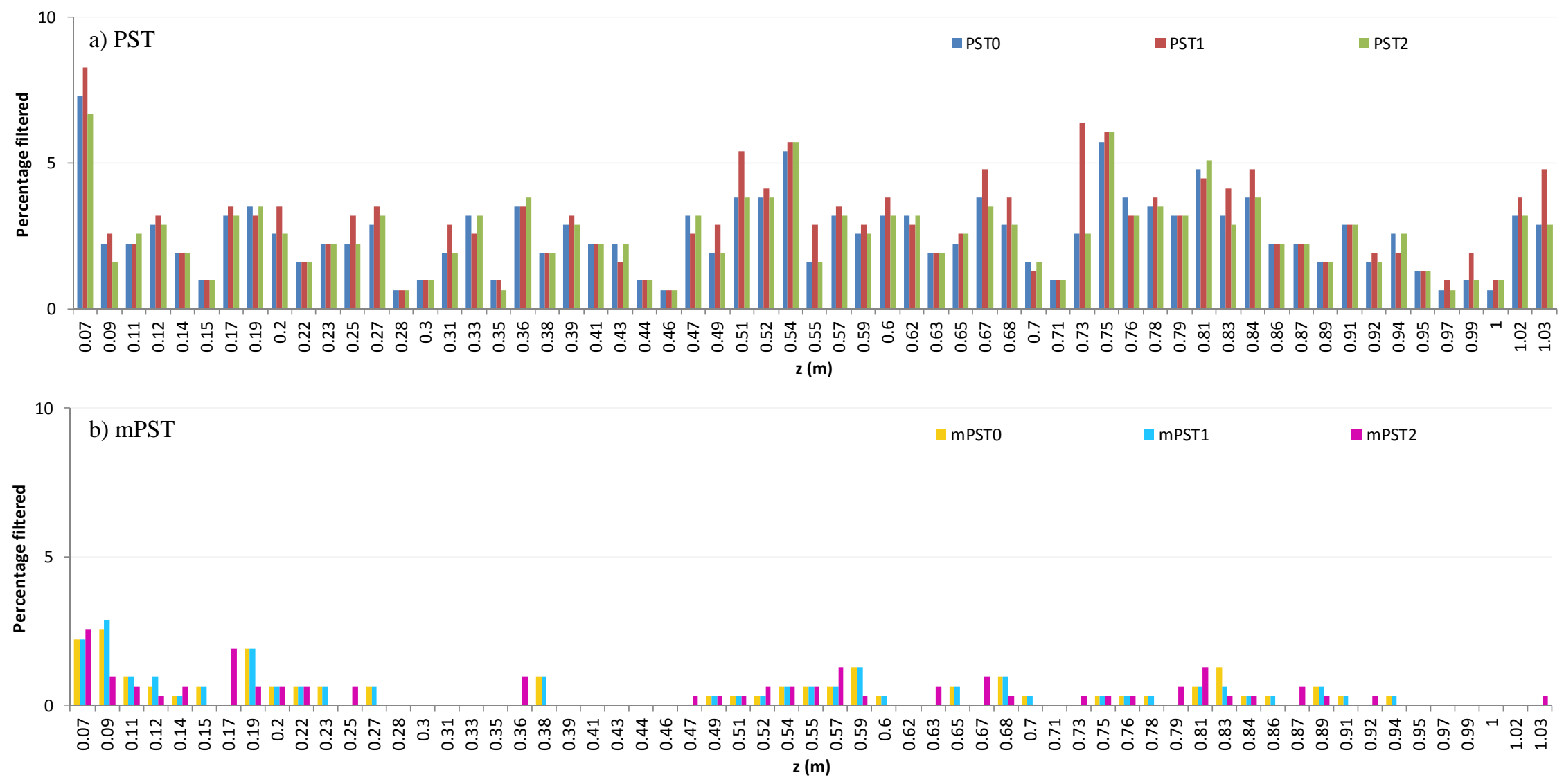

Figure A3 Number of outliers (in percent) at different bins for the $Y$ velocity component at 1.5m upstream the turbine model. 

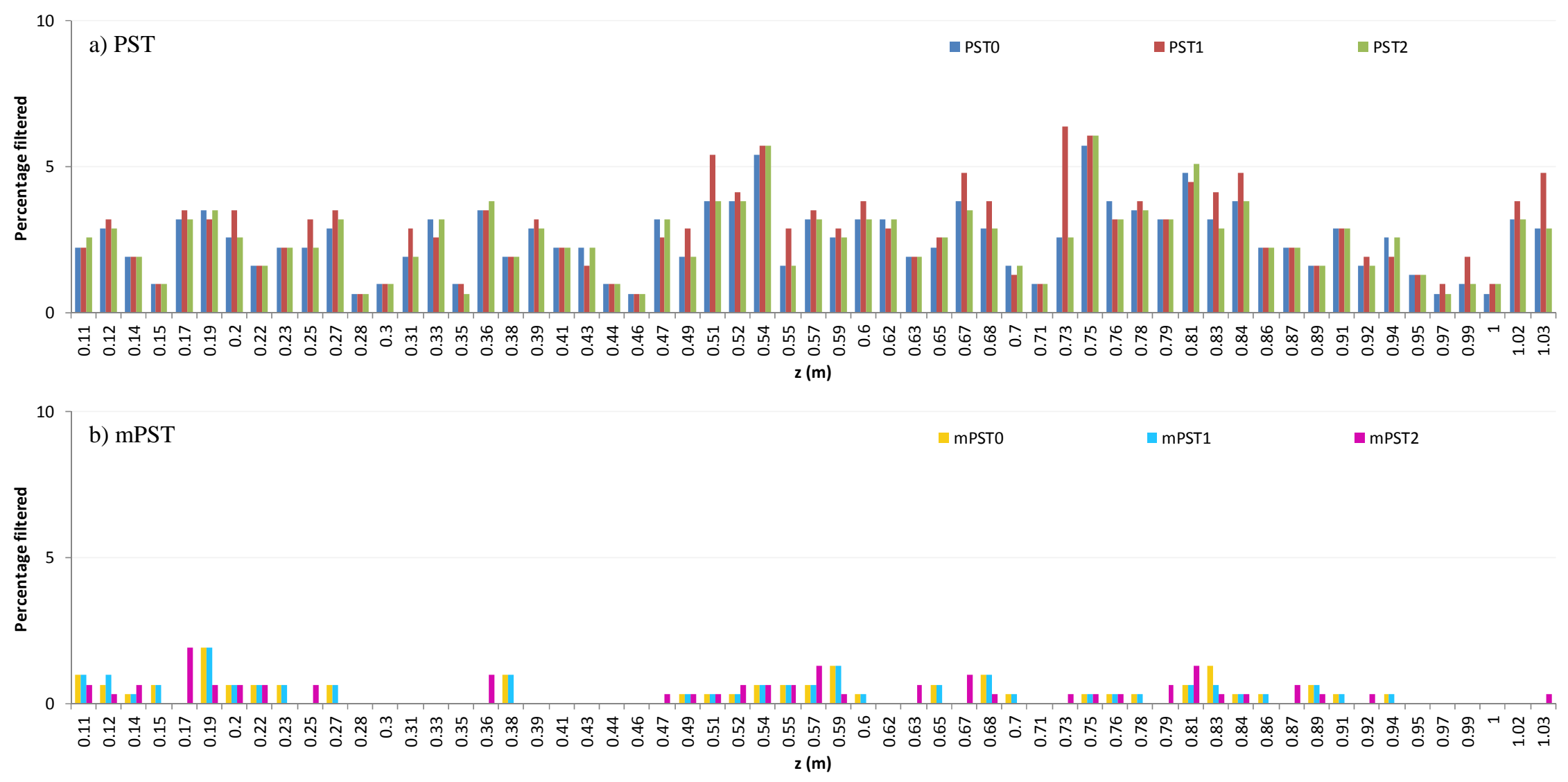

Figure A4 Number of outliers (in percent) at different bins for the $Y$ velocity component at 2.5m upstream the turbine model. 

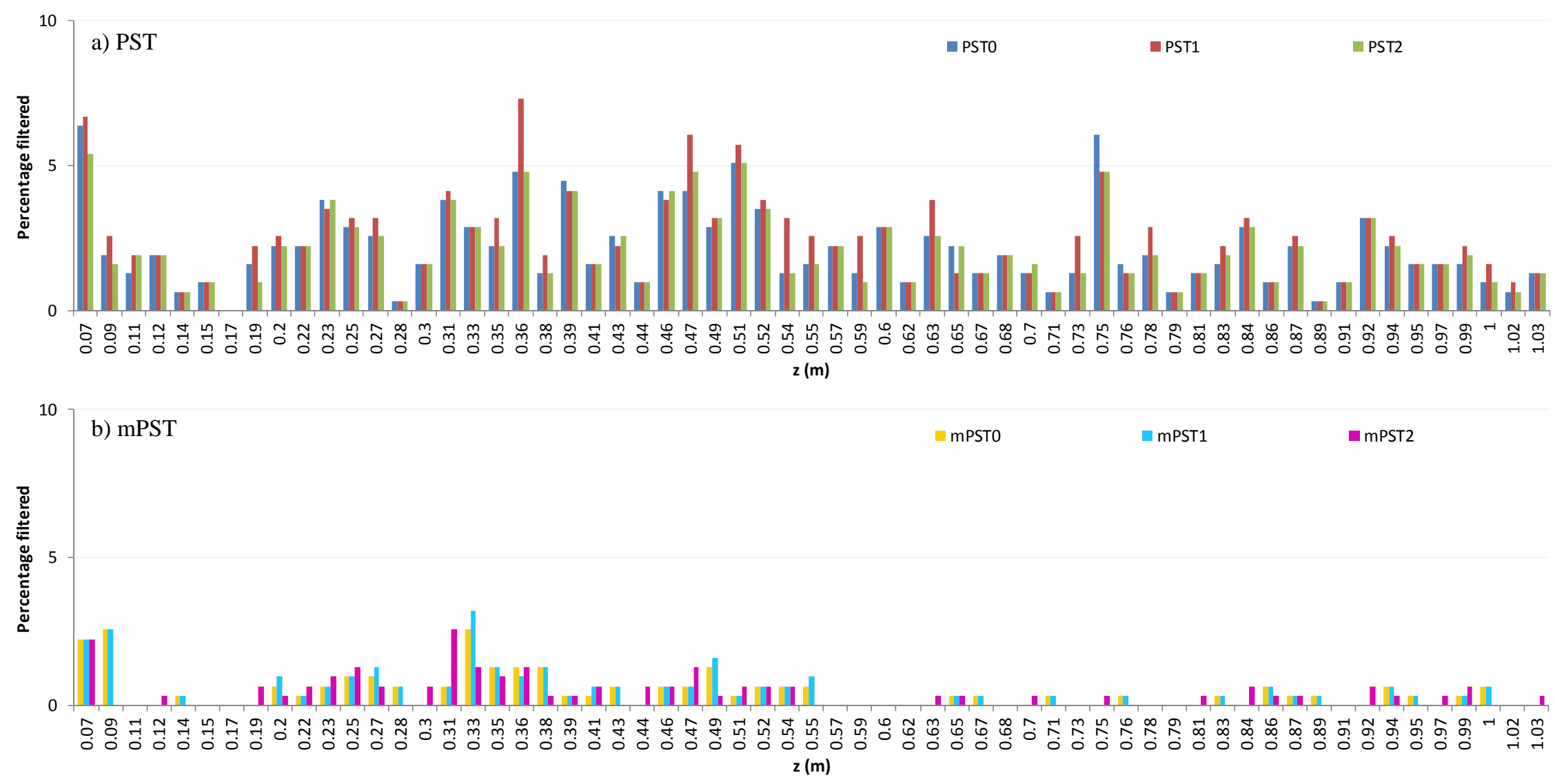

Figure A5 Number of outliers (in percent) at different bins for the $Z$ velocity component at $1.5 \mathrm{~m}$ upstream the turbine model. 

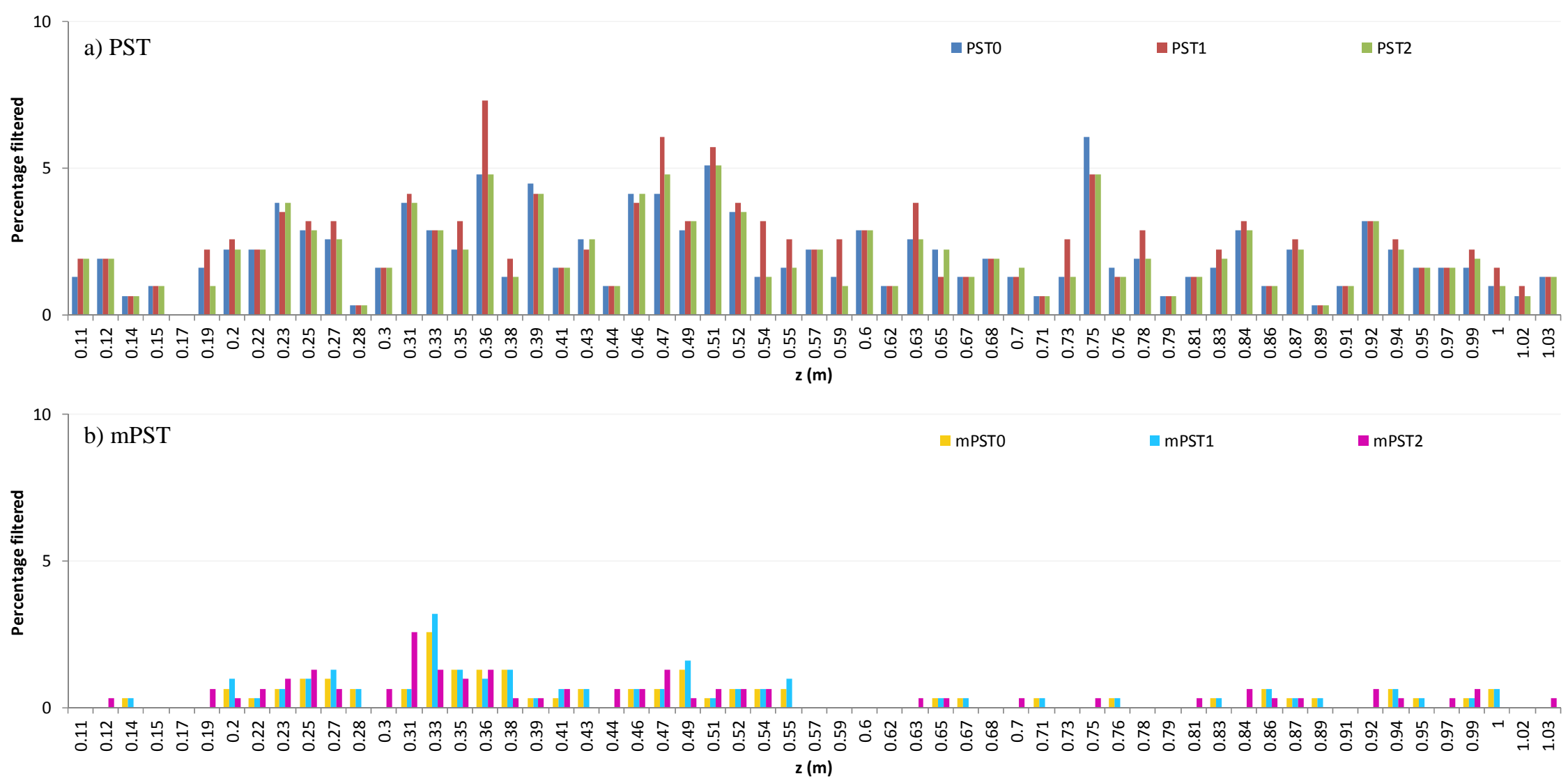

Figure A6 Number of outliers (in percent) at different bins for the $Z$ velocity component at 2.5m upstream the turbine model. 